\title{
Potential Benefits of Peroxynitrite
}

\author{
Bobby D. Nossaman ${ }^{1,2}$ and Philip J. Kadowitz ${ }^{*}, 2$ \\ ${ }^{1}$ Critical Care Medicine, Department of Anesthesiology, Ochsner Medical Center, 1514 Jefferson Highway, New \\ Orleans, Louisiana 70121 USA \\ ${ }^{2}$ Department of Pharmacology, Tulane University Medical Center, 1430 Tulane Avenue, New Orleans, Louisiana \\ 70112-2699 USA
}

\begin{abstract}
Peroxynitrite (PN) is generated by the reaction of nitric oxide (NO) and superoxide in one of the most rapid reactions in biology. Studies have reported that $\mathrm{PN}$ is a cytotoxic molecule that contributes to vascular injury in a number of disease states. However, it has become apparent that PN has beneficial effects including vasodilation, inhibition of platelet aggregation, inhibition of inflammatory cell adhesion, and protection against ischemia/reperfusion injury in the heart. It is our hypothesis that PN may serve to inactivate superoxide and prolong the actions of NO in the circulation. This manuscript reviews the beneficial effects of PN in the cardiovascular system.
\end{abstract}

Keywords: Nitric oxide/*metabolism, nitric oxide synthase/metabolism/physiology, peroxynitrous acid/metabolism, reactive nitrogen species/metabolism, reactive oxygen species/metabolism, endothelium, vascular/drug effects/metabolism, muscle, smooth, vascular/drug effects/*metabolism, vasodilator agents/adverse effects, oxidative stress/*physiology, vasodilation/drug effects.

\section{INTRODUCTION}

The endothelium releases a variety of relaxing and contracting factors that regulate the underlying smooth muscle [1]. One such molecule, nitric oxide (NO) is produced by the endothelium and participates in the modulation of blood flow, thrombosis and inflammation [2]. Although NO has been labeled as a toxic environmental pollutant, it is not toxic in low concentrations $[2,3]$. However, when produced in elevated amounts during inflammatory conditions, NO becomes toxic, as the reaction of $\mathrm{NO}$ with another oxidant, superoxide, forms the powerful oxidant, peroxynitrite (PN) $[4,5]$.

$$
\mathrm{O}_{2}^{-}+\mathrm{NO}^{\cdot} \rightarrow \mathrm{ONOO}^{-}
$$

Moreover, it is hypothesized that this molecule determines the role of NO in either physiologic $v s$ pathologic processes [3], as many of the pathological effects of NO are mediated by PN $[3,6-8]$. These pathologic effects of PN are discussed in excellent reviews elsewhere [3, 9-19].

In contrast, PN has been shown to have beneficial effects similar to those of NO and has been shown to produce vasorelaxation $[20,21]$, inhibit platelet aggregation [22, 23], and can limit ischemia-reproduction injury [24-26]. In this review, we describe the progress made in understanding the beneficial role of PN in the cardiovascular system.

\section{VASORELAXANT PROPERTIES OF PEROXYNI- TRITE}

Reperfusion of ischemic tissue initiates production of $\mathrm{NO}$ and superoxide, with subsequent formation of PN that can be

\footnotetext{
*Address correspondence to this author at the Department of Pharmacology, Tulane University Medical Center, 1430 Tulane Avenue SL83, New Orleans, Louisiana 70112-2699, USA; E-mail: pkadowi@tulane.edu
}

a significant factor in propagating ischemic injury in some, but not all, organs studied [5, 27-32]. Following the observations that PN formation may have a role in increasing coronary vasoconstriction during reperfusion of the ischemic coronary vascular bed [28]; Liu, Beckman et al. investigated the effect of PN in isolated canine coronary artery rings precontracted with PGF2a [23]. They found that PN concentrations of $10 \mathrm{nM}$ to $30 \mu \mathrm{M}$ produced consistent, rapid, and dose-dependent relaxation, regardless of the presence of the endothelium. However, PN was 7- to 10-fold less potent when compared to NO under the same experimental conditions [23], and when compared to NO-induced relaxation in other studies [33-36]. PN-induced coronary artery ring relaxation was reproducible with repeated administration of PN and the relaxation was reversible by washing with a standard bicarbonate-buffered Krebs-Henseleit solution. Although not directly reported, these findings suggest that tachyphylaxis to repeated administration of PN was not observed. When PN was allowed to decompose for $20 \mathrm{~min}$, a marked decrease in relaxation response was observed. Sodium nitrite also produced a dose-dependent relaxation, but was slower in onset and that higher concentrations were required [23]. To investigate the role of NO oxidation, the addition of superoxide dismutase (SOD) which reduces the breakdown of $\mathrm{NO}$ [37] was found to potentiate $\mathrm{PN}$-induced relaxation. In contrast, the addition to the bath of hemoglobin or methylene blue, NO scavengers [1, 38, 39], significantly decreased PN-induced relaxation [23]. The enhanced relaxation to $\mathrm{PN}$ by SOD and the inhibition of relaxation to PN by hemoglobin or methylene blue suggest that the effect of PN could be mediated by the formation of NO or by the formation of a nitroso-derivative [23]. PN has been shown to increase the formation of cyclic GMP in cultured vascular smooth muscle cells [40]. PN can be oxidized to a nitrosodioxyl radical that is in equilibrium with $\mathrm{NO}$ and molecular oxygen, which may contribute to the relaxing effects of PN 
[41]. However, responses to NO are reduced by superoxide and the interaction of $\mathrm{NO}$ with superoxide may decrease the concentration of NO available [42, 43]. This finding suggests that the decreased response to PN when compared to NO maybe due to decreased NO bioavailability. The finding that PN relaxes coronary arteries are in contrast to studies showing coronary artery vasoconstriction by PN [28]. These experiments involve short-term exposure of the coronary rings to $\mathrm{PN}$, whereas long-term $\mathrm{PN}$ exposure can induce myocardial injury [32].

$\mathrm{Wu}$, Pritchard et al. also investigated the role of PN in isolated endothelium-denuded bovine pulmonary arterial smooth muscle rings [21]. In this study, potassiumpreconstricted pulmonary arterial rings were relaxed by $0.1 \mu \mathrm{M}$ concentrations of PN. Decomposed PN and sodium nitrite, the major decomposition product of PN [44], produced slower onset of responses and are in agreement with Liu, Beckman et al. [23]. Moreover when repeatedly washed, the ring preparations could be contracted to their initial tone level with potassium chloride; and in endothelium-intact preparations incubated for $30 \mathrm{~min}$ with a high concentration of $\mathrm{PN}$, this prior treatment with $\mathrm{PN}$ did not significantly alter relaxation responses to acetylcholine, nor did the presence of the endothelium alter PN-induced relaxations. These findings suggest that $\mathrm{PN}$ does not alter vascular responses in this preparation. The mechanism of PN vasorelaxation was studied with the addition of methylene blue and LY-83583, and these inhibitors of soluble guanylate cyclase $[45,46]$ reduced $\mathrm{PN}$-induced relaxation. The use of DMSO, a tissue-permeable scavenger of hydroxyl radical [5, 47], did not affect relaxation responses to PN. These findings suggest a role of soluble guanylate cyclase with $\mathrm{PN}$, and support the findings of Liu, Beckman et al. where the administration of sodium hydroxide solutions did not alter responses to PN [23]. It was hypothesized that PN acts by two mechanisms. PN appears to initially induce relaxation via the generation of NO, as small quantities of $\mathrm{NO}$ generated from PN were detected by chemiluminescence analysis [48, 49]. However, decomposition products of $\mathrm{PN}$ also appear to contribute to the prolonged relaxation response, as sodium nitrite produced similar responses. Nitrite is thought to relax vascular smooth muscle by stimulation of soluble guanylate cyclase, after it is reduced to NO [50]. However, the small amounts of NO generated by PN or by nitrite appear unlikely to mediate responses produced by PN. A more plausible mechanism is that PN liberates NO by generating nitrosothiols by reacting with tissue sulfhydryls, since the addition of glutathione $(\mathrm{GSH})$, a tripeptide thiol [51], produced a timedependent increase in NO generation. Nitrosothiols have been shown to release $\mathrm{NO}$ and to stimulate guanylate cyclase [35, 52-54]. Moreover, pretreatment with diethyl maleate, an agent known to deplete tissue GSH [55], reduced both relaxation and formation of NO upon exposure to PN. It was concluded that PN reacts with arterial smooth muscle to generate NO that leads to initial relaxation of vascular smooth muscle, but that the decomposition products of PN also contribute to the prolonged response by the generation of a nitrosothiol-like compound that continues to release NO over prolonged periods [21].

Exposure of vascular endothelium to bacterial toxins and cytokines, as well as to macrophages and neutrophils, can generate large quantities of NO and superoxide, and these molecules and their major metabolite, PN, may be responsible for the observed hyporesponsiveness in the systemic circulation to vasoconstrictors used in the management of septic shock [2, 56-58]. Villa, Salas et al. examined coronary perfusion pressure response to $\mathrm{PN}$ and the effects of $\mathrm{PN}$ on responses to other agents [59]. In separate series of experiments, dose-dependent vasodilator responses to PN (0.3$1000 \mu \mathrm{M})$ were generated that was maximal at the $100 \mu \mathrm{M}$ dose. Repeated infusions of midrange doses of PN $(30 \mu \mathrm{M}$ and $100 \mu \mathrm{M})$ produced significant vasodilation, however the development of tachyphylaxis to PN was observed when 3 to 4 doses were administered [59]. The vasodilator effect was abolished by administration of oxyhemoglobin, an NO scavenger [38], whereas decomposed PN did not induce vasodilation [59]. In contrast to the findings of Liu, Beckman et al. and $\mathrm{Wu}$, Pritchard et al. [21,23], infusion of PN at doses of $3 \mu \mathrm{M}$ and at $1000 \mu \mathrm{M}$ significantly reduced the vasodilator responses to acetylcholine, isoproterenol, and to a Snitrosothiol, S-nitroso-N-acetyl-DL-penicil-lamine (SNAP). However, infusions of PN at midrange doses $(10,30$, and $100 \mu \mathrm{M})$ did not produce a significant reduction in the vasodilator response to these agents. The authors suggested that with the midrange doses of PN, the release of NO from PN protected against cytotoxic damage, whereas with the 1000 $\mu \mathrm{M}$ dose, the vascular damage induced by this high dose of PN overcame a protective effect of NO generated from PN [59]. The additional findings that oxyhemoglobin reduced vasodilator responses to acetylcholine, isoproterenol, and SNAP suggest that local formation of S-nitrosothiols may be responsible for the vasodilator actions of $\mathrm{PN}$, as studies have shown that in the presence of small concentrations of human plasma, albumin, or glutathione, $\mathrm{PN}$ is converted to $\mathrm{S}$ nitrosothiols or to other $\mathrm{NO}$ donors that subsequently release NO [22]. Finally, depressor responses to PN were long lived in this preparation and the vasodilator responses to isoproterenol were markedly depressed for up to 75 min following exposure to $3 \mu \mathrm{M}$ PN [59]. In contrast, coinfusion of SNAP with $3 \mu \mathrm{M}$ PN prevented the effect of PN seen in the response to these vasodilators. The findings of tachyphylaxis and vascular dysfunction seen with PN are in contrast to the results of Liu, Beckman et al. [23] and of Wu, Pritchard et al. [21]. Although PN initially produced vasodilatation, tachyphylaxis rapidly developed, and these results and other studies $[5,22,44,57,58]$, provided experimental evidence in support of the hypothesis that PN may lead to irreversible endothelial-dependent and endothelial-independent vascular damage [59].

PN reacts with GSH to form S-nitrosothiols that generate NO, which may be a detoxification pathway [22], and has been shown to be a relaxant in isolated or intact vasculature $[21,23,59]$, and that this action of PN may be due to nitrosylation of tissue thiols [21]. Moro, Darley-Usmar et al. examined the role of PN on isolated rabbit aortic strips [60] denuded of endothelium and superfused in a cascade bioassay [61]. The addition of PN $(30-300 \mu \mathrm{M})$ to the superfusate resulted in concentration-dependent relaxations of all three detector strips and these observed relaxations were inhibited by oxyhemoglobin [61]. These results confirmed previous studies in bovine pulmonary arterial rings [21], canine coronary arterial rings [23], and in the coronary vasculature in the isolated rat heart [59]. However, the results obtained in this series of experiments did not demonstrate the development 
of tachyphylaxis in contrast to the findings in the isolated rat heart preparation [59]. These differences in results could be due to the dilutional effects of the medium or buffers used in this series of experiments, whereas PN was directly injected into the isolated rat heart preparation [59]. As relaxations to $\mathrm{PN}$ were similar in the cascade bioassay, it was deduced that a stable NO donor was formed from the reaction of PN with the Krebs buffer in the superfusate. The authors repeated the experiments incubating PN in Krebs buffer without glucose and found that PN had little relaxant effect suggesting that PN reacted with glucose in the Krebs buffer to form compounds that caused relaxation [61]. The finding that the duration of responses to PN was greater than 20 seconds suggested that the observed vasorelaxations arise from the formation of compounds that can act as NO donors [5, 22, 62]. Moreover, the addition of D-glucose, or L-glucose to PN in the superfusate, suggests that $\mathrm{PN}$ can react with organic molecules, including sugars and bicarbonate, to form an NO donor [5, 41, 58, 61, 63]. However when electrochemically assayed, the reaction between $\mathrm{PN}$ and glucose to generate NO required both $\mathrm{Cu}^{++}$and L-cysteine, a requirement similar to that found for other organic nitrates, such as nitroglycerin (GTN), or to nitrites such as amyl nitrite [64-66]. Additionally, PN reacted with L-glucose as well as to other molecules with functional alcohol groups such as fructose, glycerol, or glyceraldehyde [61].

In pathologic situations, recruited macrophages and neutrophils can be activated to produce both superoxide and NO as part of the inflammatory response $[2,57,58]$. The balance between these two radicals, and formation of PN may result in pathologic effects with alteration in vascular reactivity and blood flow in the human placenta. Prior studies have shown the placental villus has the ability to generate and respond to NO [67]. Holcberg, Kossenjans et al. studied the interactions of NO and superoxide in the vasculature of isolated perfused human placental cotyledons preconstricted with the thromboxane agonist, U46619 [68], with fetal perfusion pressure used as an index of vascular response [69]. It was observed that infusion of superoxide $(\sim 0.53 \mu \mathrm{M} / \mathrm{L})$ produced a mild vasoconstriction in the perfused placental cotyledons, and that the infusion of NO produced vasodilatation, but that the infusion of both radicals together produced a greater vasodilatation than NO alone [69]. It was concluded that although superoxide decreased the vasodilator action of NO, the interaction of the two radicals produced a more potent vasodilator, which may be PN in the placental vasculature [69].

Excessive production of $\mathrm{NO}$ and nitrogen metabolites have been shown to worsen lung injury in a hyperoxic animal model, as the administration of L-arginine produced pulmonary hypertension and edema, whereas the administration of L-NAME, a NOS inhibitor [56], or SOD, which scavenges superoxide [42], attenuated the pathologic responses to of L-arginine, suggesting that NO, superoxide, or PN may contribute to acute lung injury during hyperoxia [70]. Certainly, the production of NO in large quantities by cytokine-induced NOS has been implicated in vascular dysfunction seen in septic shock and other inflammatory states $[56,71]$, but how these pathological changes in vascular tone are mediated are not fully known [71]. The generation of NO and superoxide can lead to formation of PN and hydroxyl radicals [58]. Kooy, Royall et al. investigated the role of PN in the pathology of vascular dysfunction in inflammatory states in a mesenteric, renal, and hindquarters flow velocity model in the rat [72]. These authors found that PN in repeated iv doses of $10 \mu \mathrm{M} / \mathrm{kg}$ decreased mean arterial pressure and hindquarters and mesenteric vascular resistance. However, with repeated exposure to $\mathrm{PN}$, a progressive decrease in the response to PN was observed, with a progressive development of increased systemic arterial pressure. Following the development of tachyphylaxis to PN, there were decreased responses to vasodilating and vasoconstricting catecholamines. The authors found that $\mathrm{PN}$ is a potent systemic vasodepressor but that tachyphylaxis rapidly developed. PN may be an important factor in vascular pathology seen in sepsis and other inflammatory conditions [72].

Vascular dysfunction, a common feature of the systemic inflammatory response syndrome (SIRS) [73], may be mediated by the pathological production of $\mathrm{NO}$ or indirectly through formation of secondary reaction products $[56,74]$. The development of tachyphylaxis following repeated administrations to PN, and the subsequent development of hypertension along with vascular depression in response to exogenous catecholamines [72], led Kooy \& Lewis to further examine the role of PN in the development of systemic hypertension [75]. The effects of repeated administrations of PN $10 \mu \mathrm{M} / \mathrm{kg}$ iv in anesthetized rats with Doppler flow probes initially produced marked reductions in mean arterial pressure and significant decreases in hindquarters and mesenteric resistance, but with minor decreases in renal resistance [75]. However, subsequent injections of PN produced smaller responses so that by the $10^{\text {th }}$ injection, changes in mean pressure were approximately $12 \%$ of control, changes in hindquarters resistance were approximately $17 \%$ of control, and changes in mesenteric resistance were approximately $12 \%$ of control [75]. Moreover during these experiments, a gradual sustained increase in mean arterial pressure and in vascular resistance developed within 30-60 min, and was most prominent at $2 \mathrm{hrs}$. By comparison, these hemodynamic values did not change over time in control animals [75]. It was suggested that endogenous PN might deplete reduced thiols, by decreasing S-nitrosothiol formation, such as S-nitrosocysteine, or alter the process by which Snitrosothiols relax vascular smooth muscle. The most abundant source of free sulfhydryl groups in mammalian tissue is cysteine, and is readily available for the formation of nitrosothiols [76]. Although S-nitrosothiols are hypothesized to be responsible for the vasorelaxant properties of $\mathrm{PN}$ [21] and of NO [54, 77], and as PN is a potent oxidant capable of sulfhydryl oxidation [44], inhibition of S-nitrosothiols might promote increases in vascular tone [75]. Finally, in these experiments, the increases in tone were unlikely due to augmented sympathetic neurogenic vasomotor tone as the catecholamines used in these experiments, norepinephrine and epinephrine, were found to produce substantially smaller responses in PN-tolerant rats [75].

The production of NO and oxygen radicals during ischemia or hypoxia followed by reperfusion may contribute to cerebral injury [29]. During cerebral ischemia/hypoxia calcium accumulates, which upon oxygen resupply during reperfusion activates neuronal NO synthetase that oxidizes arginine and produces NO. NO reacts with superoxide, which is also produced during reperfusion, to form PN, and also the powerful and cytotoxic oxidants, hydroxyl radical and nitrogen dioxide [29]. Superoxide, hydrogen peroxide, 
and hydroxyl radicals are reported to be strongly vasoactive $[21,23,78-80]$. Brain metabolism regulates cerebral blood flow, and studies suggest that changes in extracellular potassium concentration link brain metabolic activity with blood flow [81]. Wei, Kontos et al. examined the effects of PN and the role of potassium channels following topical application of hydrogen peroxide, superoxide, and $\mathrm{PN}$ in doses of 1,3 and $5 \mu \mathrm{M}$ to cerebral arterioles of the anesthetized cat with cranial windows [82]. Neither the topical application of LY83583 , a soluble guanylate cyclase inhibitor [21, 83, 84], nor tetraethylammonium (TEA), a calcium-activated potassium channel inhibitor [81, 85], affected the vasodilator action of hydrogen peroxide. However glyburide, an ATP-sensitive potassium channel inhibitor [83], inhibited the vasodilator response to hydrogen peroxide or PN, whereas LY-83583 had no effect [82]. In contrast, the vasodilation observed from superoxide was only significantly reduced by TEA [82]. These authors found that vasorelaxant action of both hydrogen peroxide and PN were dependent on activation of ATP-sensitive potassium channels, whereas the vasodilator action of superoxide was dependent upon opening of calcium-activated potassium channels. In contrast to the findings of $\mathrm{Wu}$, Pritchard et al. and of Liu, Beckman et al. [21, 23] activation by $\mathrm{PN}$ at low concentrations of soluble guanylate cyclase does not appear to play a role in the cerebral vasodilator actions of hydrogen peroxide, superoxide, or PN; whereas at higher non-physiologic concentrations, an effect similar to that as reported in pulmonary and coronary vessels were observed $[21,23]$. Their findings suggest that PN, as well as hydrogen peroxide, probably act through an oxidant mechanism and either reduce the concentration of ATP by interfering with cellular metabolism, or that these oxidants open ATP-sensitive potassium channels [82].

PN has been found to inhibit cellular respiration that may contribute to endothelial dysfunction [7, 86-91]. Recent studies have shown that $\mathrm{NO}$ at high concentrations, as well as $\mathrm{PN}$, can activate poly(adenosine 5'-diphos-phoribose) synthase (PARS) $[87,89]$ which consumes energy, resulting in cell death through depletion of beta-nicotinamide adenine dinucleotide $\left(\mathrm{NAD}^{+}\right)$and adenosine triphosphate (ATP) [92, 93]. PARS is involved in DNA repair [94, 95], cell differentiation [96, 97], and control of the cell cycle [98, 99]. Recent studies in rat aortic rings exposed to PN demonstrate a dosedependent reduction in vascular contractility, with a significant increase in PARS activity [100]. As the pulmonary circulation is a prime site for PN formation [101-104], Chabot, Mitchell et al. investigated the role of PARS activation during PN stimulation in the pulmonary vascular bed of the rat, and the role of PN on vascular responses to endothelialdependent and independent agents [105]. These authors observed under baseline conditions in their isolated pulmonary arterial ring preparation, $\mathrm{PN}(10 \mathrm{nM}$ to $100 \mu \mathrm{M})$ had no significant effect on resting tone, whereas under elevated tone conditions with the potent thromboxane mimetic, U46619 $[68,106]$, PN produced concentration-dependent relaxations [105], whereas the responses to decomposed PN were significantly depressed when compared to fresh PN at the highest dose studied. Furthermore, PN relaxed precontracted pulmonary arterial rings at concentrations that did not induce endothelial dysfunction as responses to acetylcholine were reproducible when compared to control and in fact, at the highest concentrations studied in this preparation, PN aug- mented relaxations induced by the endothelium-dependent vasodilator agent [105]. The vasodilator effect of PN on rat pulmonary arteries occurred in concentrations that were in agreement with values observed in canine coronary arteries [23], in rat coronary arteries [59], and in bovine pulmonary arteries [21]. The findings that PN did not decrease the response to acetylcholine, and at higher concentrations, enhanced responses to acetylcholine, suggest that PN does not impair the ability of the endothelium to release NO, and in fact may enhance responses [105]. In the presence of PARS inhibition with 3-aminobenzamide [93, 107], PN inducedrelaxations were significantly inhibited, whereas PARS inhibition had no effect on the relaxation response to endothelium-derived NO [105]. In contrast, responses to PN were not affected by a NO synthase inhibitor or in the presence of SOD. In contrast to Liu, Beckman et al. [23], these findings suggest that superoxide has no role in mediating responses to PN, nor does PN act by stimulating the release of NO from the endothelium. However, the PARS inhibitor significantly reduced the relaxation response to PN. In contrast to the effects on PN, little to no effect on the relaxation produced by acetylcholine or by sodium nitrite was observed during PARS inhibition, whereas the relaxation increased following administration of sodium nitroprusside. The authors suggest that PN, but not to endothelial-derived $\mathrm{NO}$, can activate PARS and result in rapid depletion of ATP with a consequent reduction in pulmonary vascular tone [105]. Although the PARS inhibitor blunted responses to PN, but not to acetylcholine, suggest that $\mathrm{NO}$ and $\mathrm{PN}$ induce relaxation by different mechanisms $[56,57]$. The observations that $\mathrm{PN}$ is responsible for the vascular hyporesponsiveness together with other findings of PN toxicity [5, 7, 22, 44, 57-59, 90, 91, 100], suggest that inhibitors of PARS may reduce the persistent hypotension seen in sepsis or other inflammatory conditions without affecting the actions of endotheliumderived NO [105]. These findings are in contrast with Villa, Salas et al. that PN induced vascular dysfunction, including impairment of responses to acetylcholine [59].

NO has been reported to regulate coronary vascular tone through stimulation of soluble guanylate cyclase [20,38]. $\mathrm{PN}$ reacts with thiols to form compounds, including nitrosothiols, with reported vasodilator activity [22, 61, 108-110]. GSH synthesized from glutamate, cysteine, and glycine [111], is the most abundant group of nonprotein thiols found in animal cells, and is probably the most important intracellular antioxidant [111], as evolutionary evidence suggests that GSH evolved as a molecule to protect against oxidant toxicity [112]. GSH is oxidized to glutathione disulfide (GSSG) by GSH peroxidase, an important enzyme known for antioxidant actions, as GSH peroxidase protects the cell against reactive oxygen species including $\mathrm{PN}$ and can inhibit enzymes such as lipoxygenases, NO synthases, and NADPH oxidase [113-115]. GSH and GSSG have also been reported to relax isolated canine coronary arteries [116], however the actions of thiols in the control of coronary vascular tone in the intact heart are unknown. Cheung and Schulz examined the effects of GSH and related compounds, GSSG, GSH ethyl ester, and L-cysteine, in isolated rat hearts perfused with Krebs buffer by the Langendorff method [117]. GSH, GSSG, and GSH ethyl ester, but not L-cysteine, produced a concentration-dependent increase in coronary flow [117], and the data suggest that the vasodilation was mediated by 
an NO-guanylate cyclase dependent mechanism as the NO synthase inhibitor, NG-monomethyl-L-arginine, prevented the GSH induced increase in coronary flow and attenuated responses to GSSG. Moreover, a specific soluble guanylate cyclase inhibitor [118], abolished vasodilator responses to GSH and to GSSG, and significantly decreased the increases in myocardial cGMP levels, suggesting a role for a soluble guanylate cyclase-dependent mechanism. Additionally, the vasodilator actions of GSH were significantly reduced by SOD [37], suggesting a role of an NO dependent mechanism. Inhibition of GSH reductase, the enzyme that regenerates GSH from oxidized GSSG, abolished GSSG-induced vasodilation [119]. Finally, neither the administration of glibenclamide, an ATP-sensitive potassium channel antagonist [120], or of a non-steroidal anti-inflammatory drug, indomethacin [121], affected the vasodilator actions of GSH and GSSG. The authors concluded that the observed coronary vasodilation from GSH and from GSSG in this model was mediated by an NO- and guanylate cyclase-dependent mechanism, induced by the reactions between GSH and PN to form S-nitrosoglutathione, a NO donor [117]. Endothelial cells have been shown to produce NO and superoxide [122], and that PN can be produced when stimulated [90]. Studies have shown that the vasodilator actions of PN depend upon reaction with thiols, in particular GSH, to form Snitrosoglutathione [22, 109]. As both $\mathrm{NO}$ and superoxide depend on GSH for their vasodilator effects, these data suggest that there is a significant basal production of $\mathrm{PN}$ in the isolated heart [117]. Moreover, S-nitrosoglutathione is a potent $\mathrm{NO}$ donor that is active at nanomolar concentrations $[109,123]$.

Although several studies have shown that under physiological conditions, PN produces prolonged vasorelaxant responses [21, 23, 59, 61], however this relaxant action cannot be due to the direct action of PN, because of inherent instability at physiological $\mathrm{pH}[5,124]$. Moreover, Moro, DarleyUsmar et al. demonstrated that the vasorelaxant effects of PN were due to the formation of a secondary, more stable species following reaction with glucose [61]. Dowell and Martin further characterized the actions of PN in isolated rat aortic rings, and also investigated the reactions of PN with D-glucose and with related substances containing functional alcohol groups [125]. Under elevated tone conditions, micromolar concentrations $(1 \mu \mathrm{M}-100 \mu \mathrm{M})$ of PN induced a concentration-dependent relaxation of aortic rings that were maximal when the rings were denuded of endothelium. Prior incubation of endothelial-absent rings with hemoglobin, a scavenger of $\mathrm{NO}[1,34,64,65]$ or incubation with methylene blue, attenuated the response to PN [125]. Although endothelium-present rings were significantly less sensitive to PN, incubation with the NOS inhibitor, L-NAME [126-128], in endothelium-intact rings enhanced this latter effect [125]. Administration of neutralized (decomposed) PN also produced smaller concentration-dependent relaxations, were similar to relaxations produced by comparable concentrations of sodium nitrite, and were without effect when residual nitrite was removed from the neutralized PN solution [125]. These findings were comparable to the findings of Liu, Beckman et al. who also observed that relaxation responses to decomposed PN was slower in onset and lower in magnitude in both endothelium-present and endotheliumdenuded rings preparations [23]. Moreover, the authors demonstrated that the observed relaxation from PN was reproducible over a 6 hour period and is in contrast with the development of tachyphylaxis as reported by Villa, Salas et al. [59]. Following washout of endothelium-containing ring preparations incubated with high concentrations of PN, there was no effect on subsequent relaxation response to acetylcholine, but a significant depression of subsequent contractions to phenylephrine was observed however, this suppression was reversed in $2 \mathrm{~h}$, or with prior incubation with the nonselective soluble guanylate cyclase inhibitor, methylene blue $[34,54,64]$ in the ring preparation [125]. The finding of no significant long-term modulation of phenylephrineinduced contractions by PN is in contrast to the results of Kooy, Royall et al. who found attenuation of responses to catecholamines following the development of tachyphylaxis to PN [72]. When D-glucose was added to PN, a more potent relaxant effect was produced in endothelium-absent rings when compared to PN alone [125], whereas the addition of D-glucose with neutralized PN, no increase in relaxant effect was observed [125]. The substitution of glycerol for Dglucose also reacted with PN to produce a potent vasorelaxant response. As thiols have been shown to enhance the release of NO by a number of compounds [35, 52-54], the effects of the thiol-containing amino acid, L-cysteine, were examined. L-cysteine in the presence of PN had no effect on aortic ring tone, but when added to the reaction products of PN and D-glucose or glycerol, L-cysteine potentiated the relaxant actions [125]. However, the addition of membrane impermeant sugars, mannitol or sorbitol, with PN demonstrated no new relaxant activity, but relaxation was potentiated by the presence of L-cysteine. In contrast, when PN was mixed with L-glucose (impermeant sugar) a new substance with potent relaxant properties was formed, which was also potentiated by the presence of L-cysteine [125]. Their findings are in contrast with Moro, Darley-Usmar et al. in that relaxation was dependent upon the concentration of glucose in the perfusion medium [61]. It is possible that the reaction between PN and glucose in these experiments forms an organic nitrate or nitrite, as prior experiments have shown that both GTN and amyl nitrite release NO in the presence of thiols, such as L-cysteine $[65,129,130]$. Moreover, PN had been shown to react with plasma thiols [63], and with albumin [57]. These experiments demonstrated that PN can react with glucose and other compounds with functional alcohol groups to form vasorelaxant species, but that $\mathrm{PN}$ as studied in this preparation is not dependent upon this reaction for expression of vasorelaxant activity [125].

Prior studies have shown that the actions of NO involve stimulation of guanylate cyclase [2, 21, 23], and of a role for tissue GSH in the vascular relaxation response to PN [21, $117,131]$. Moreover, PN induces accumulation of cGMP in a GSH-dependent manner in endothelial and smooth muscle cells, and PN produces thiol-dependent stimulation of purified guanylate cyclase [109]. Davidson, Kaminski et al. found that micromolar concentrations of nitrogen dioxide, a key metabolite of $\mathrm{NO}$, produced prolonged relaxation of isolated endothelium-denuded rings of bovine pulmonary arteries precontracted with potassium [131]. Additionally, it was found that relaxation in response to nitrogen dioxide involved the nitrosation of GSH, and possibly other tissue thiols, to release NO over prolonged periods of time. Moreover, it was concluded that chronic exposure to PN and to 
nitrogen dioxide causes tissue GSH depletion and the cytotoxic aspects of these reactive nitrogen species [29, 44, 57, 91, 132-135] are expressed [131]. In a subsequent study, Davidson, Kaminski et al. examined the role of endogenous PN formation in endothelium-denuded bovine pulmonary arterial rings during elevated levels of NO [136]. These authors questioned the role of the large concentrations of both PN and NO necessary to obtain vascular relaxation in various preparations $[21,23,131]$. The exposure of precontracted rings to nanomolar concentrations of $\mathrm{NO}(50 \mathrm{nM})$ produced prolonged relaxation and an increase in endogenous release of NO, which was reduced following depletion of tissue GSH with diethyl maleate (DEM) [21, 131]. Moreover, the induced NO relaxation in this preparation was reversed by methylene blue, a known guanylate cyclase inhibitor $[21,34,38,45,54]$, or by oxyhemoglobin, a scavenger of NO $[38,59,61]$. The authors also found that by inhibiting superoxide production with diphenyliodonium, an agent that interferes with the catalytic cycle at the flavin site [137, $138]$, or by scavenging superoxide with SOD $[20,37,38,45$, $46,54,76,139]$ or with Tiron [140-142], the NO-mediated relaxation was reversed [136]. Moreover during exposure to exogenous $\mathrm{NO}$, a marked increase in PN formation was detected, suggesting that $\mathrm{PN}$ participates in prolonging the initial relaxation to $\mathrm{NO}$ either through a thiol trapping of $\mathrm{NO}$ or through NO regeneration [136].

The role of tissue thiols as a target of PN is supported by the evidence that PN oxidizes plasma thiols [63], albumin [44], as well as glutathione in erythrocytes [143]. Glutathione enhances PN to release NO and activates soluble guanylate cyclase $[21,109]$ and the use of thiol-depleting agents block PN-induced elevation of cyclic GMP [109], and block the release of $\mathrm{NO}$ and relaxation in bovine pulmonary arteries [21]. Furthermore, PN has been shown to react with sugars and compounds with alcohol side groups to form nitrated or nitrosated derivatives with NO-releasing properties $[61,125]$ that can be enhanced by glutathione or L-cysteine $[61,125]$. Enhanced release of NO from thiols has been shown with a wide variety of organic nitrates and nitrites [130]. However uncertainty exists as to which of the functional groups of L-cysteine, thiol, amino, and/or carboxylic acid are involved in the release of NO. Dowell and Martin investigated four groups of compounds; 1) analogues with a free thiol group with or without a free amino or carboxylic acid group such as D-cysteine, the optical isomer of Lcysteine; L-cysteine ethyl ester, an esterified carboxylic acid; $\mathrm{N}$-acetyl-L-cysteine, a compound with an acetylated amine; and reduced glutathione, a tri-peptide containing L-cysteine; 2) analogues lacking a free thiol but retaining a free amino and carboxylic acid groups, such as S-methyl-L-cysteine, a methylated thiol group; oxidized glutathione, two molecules of glutathione conjugated through a disulphide bridge; and L-alanine, another amino acid that is similar in structure to L-cysteine but lacking the thiol functional group; 3) analogues retaining an amino group but lacking a free thiol or carboxylic acid group, such as L-cystine diethyl ester, a compound containing two molecules of L-cysteine ethyl ester conjugated through a disulphide bridge; and L-alanine ethyl ester, L-alanine with an esterified carboxylic acid group; and finally 4) N-acetyl-L-alanine, L-alanine with an acetylated amine group, a compound that lacks free thiol and amino groups but retains the carboxylic acid function. Dow- ell and Martin [144] investigated the interactions of PN with these compounds in isolated endothelium-denuded rat aortic rings under similar conditions to that described by Martin, Furchgott et al. [145]. In these experiments, these authors found that a micromolar concentration of PN $(1 \mu \mathrm{M})$ incubated for $10 \mathrm{~min}$ in the aortic ring preparation, followed by repeated washing, produced profound depression of phenylephrine-induced contraction, that could be maintained for at least 1 hour, but was reversible [144]. As PN has a short half-life $[5,124]$, these results suggest $\mathrm{PN}$ reacts to form NO-releasing found in the vascular rings or with constituents in the bathing medium. These results also confirmed that PN has little to no effect on long-term depression of endothelialinduced vasoconstriction [125], which are in contrast with the findings of Villa, Salas et al. [59]. As thiols enhance the release of NO from a variety of compounds [146], administration of reduced glutathione or of L-cysteine were without effect on control rings (phenylephrine-contracted), however, micromolar concentrations of PN, followed by the addition of L-cysteine, or analogues of L-cysteine that contain a free thiol group such as D-cysteine, L-cysteine ethyl ester, $\mathrm{N}$ acetyl-L-cysteine or reduced glutathione, induced relaxation of similar magnitude to that observed with L-cysteine [144]. In contrast, analogues lacking free thiols such as S-methylL-cysteine, L-alanine, or oxidized glutathione, induced no relaxation to phenylephrine contracted rings following exposure to PN [144]. These data suggest that analogues containing free thiols are necessary for the formation of NOreleasing compounds [144]. Furthermore, these authors investigated analogues lacking a free thiol group, but retaining the amino group, such as L-cystine diethyl ester and Lalanine ethyl ester and found that these analogues once mixed with PN, formed products with potencies similar to that of analogues lacking only the thiol group [144]. Finally $\mathrm{N}$-acetyl-L-alanine, a compound with a substituted amino group that lacks a free thiol, failed to generate relaxant activity following exposure to PN [144]. In summary, PN when combined with species containing a free thiol group generated similar relaxant responses, but when mixed with analogues lacking thiols, formed products with relaxant activities significantly less potent than when compared to Lcysteine, and that analogues with a free amino group, but no thiol or carboxylic group function, formed products with similar relaxant properties to compounds lacking only the thiol group. It appears that $\mathrm{PN}$ can react with L-cysteine to form novel relaxants in which the activity is derived from the formation of a S-nitrosothiol, and with less activity when forming a N-nitroso derivative [144].

Studies from several laboratories suggest that vascular smooth muscle relaxation induced by nitrogen-oxide containing vasodilators such as GTN, SNP and nicorandil are mediated by increases in the levels of the second messenger, cyclic GMP [34, 147]. It is also known that the cholinergic neurotransmitter, acetylcholine, also indirectly utilizes cyclic GMP as a second messenger to cause vasodilation [1]. However, the mechanisms by which cyclic GMP produce relaxation of vascular smooth muscle remain to be defined. The effect of cyclic GMP on smooth muscle calcium homeostasis such as plasma membrane $\mathrm{Ca}^{++}$influx, sarcoplasmic reticulum $\mathrm{Ca}^{++}$release, and plasma membrane $\mathrm{Ca}^{++}$extrusion have been studied [148-151]. The role of potassium channels in hyperpolarization induced by nitrates and by acetylcholine 
has been investigated $[152,153]$. Benkusky, Lewis et al. examined the role of ATP-sensitive potassium channels in the response to $\mathrm{PN}$ in the pentobarbital-anesthetized rat [72, 75]. $\mathrm{PN}$ in doses of 1 to $10 \mu \mathrm{M} / \mathrm{kg}$ produced dose-dependent decreases in mean arterial pressure and in hindquarters and mesenteric vascular resistances, but with repeated $10 \mu \mathrm{M} / \mathrm{kg}$ injections, tachyphylaxis occurred [154]. Moreover, following the development of tachyphylaxis to $\mathrm{PN}$, responses to acetylcholine and of prostacyclin were attenuated, whereas responses to an NO donor were not changed [154]. Responses to acetylcholine and to prostacyclin were depressed following the development of tachyphylaxis to PN. These results confirm earlier results that PN is a significant vasodilator in the systemic circulation of the rat, and that tachyphylaxis develops $[72,75]$, and subsequently induces hypertension [75]. Tachyphylaxis to PN also reduces responses to acetylcholine and to prostacyclin, by blocking smooth muscle ATP-sensitive potassium channels [154], as recent work has shown that PN may hyperpolarize vascular smooth muscle by activation of ATP-sensitive potassium channels [82].

A number of proteins with cysteine residues can be nitrosated [110, 155]. Both S-nitrosylated low-molecular weight thiols, such as S-nitrosoglutathione, and protein thiols, such as S-nitrosoalbumin, have been detected in biological fluids as a consequence of endogenous nitrogen-oxide metabolism and exogenous NO administration [156, 157]. S-nitrosothiols can serve as NO donors when activated by homolytic cleavage to form NO radicals $[158,159]$, and it is possible that the hemodynamic effects of organic nitrates and PN may involve the formation of biologically active S-nitrosothiols [21-23, $54,59]$. Prior investigations with L-penicillamine, a natural degradation product of all penicillins has structural resemblance to the amino acids, cysteine, methionine, valine, and threonine [160], have shown that this agent attenuated vasodilator responses to L-S-nitrosocysteine [161, 162] suggesting that L-penicillamine blocks S-nitrosothiol recognition sites. Graves, Lewis et al., 1998 [163] examined the role of S-nitrosothiols and PN in pentobarbital-anesthetized rats [72, 75]. PN $(0.5 \mu \mathrm{M}-10 \mu \mathrm{M})$. The S-nitrosothiols (L-S-nitrosocysteine, L-S-nitroso-glutathione, S-nitrosoalbumin) produced dose-dependent decreases in mean arterial pressure and in mesenteric and hindquarter vascular resistances whereas decomposed PN produced minor effects [163]. Whereas the hypotensive and vasodilator effects of the Snitrosothiols were significantly reduced following administration of L-penicillamine, the hemodynamic actions of PN were not affected by the S-nitrosothiol recognition site inhibitor [163]. These findings suggest that in the systemic circulation, formation of low-molecular-weight S-nitrosothiols are unlikely to be primarily responsible for the hemodynamic effects of PN [163]. These findings also give indirect support to the hypothesis that the mechanism of PN may be due to activation of soluble guanylate cyclase and the subsequent generation of cGMP, as these findings are supported by other studies showing that inhibition of guanylate cyclase markedly attenuated the relaxation observed by PN in isolated pulmonary arteries [21], and that SOD potentiated the vasorelaxant effects of PN [22], and/or PN-mediated vasorelaxation may occur through hyperpolarization of vascular smooth muscle through activation of ATP-sensitive potassium channels [163].
Reactive nitrogen and oxygen species, such as $\mathrm{PN}$, are continuously generated and play important roles in pathologic processes $[22,56,58,164-166]$. Endogenous antioxidants constitute the first line of defense against oxidantinduced injury, but under chronic pathologic conditions, these defenses can be overwhelmed allowing these reactive species to target tissues and impair important processes [63, 167-169]. A major extracellular antioxidant, uric acid, may minimize PN-mediated damage to tissues [63, 100, 170]. In this study, Skinner, White et al. examined the reaction between uric acid and $\mathrm{PN}$ in vessel reactivity studies in an isolated aortic ring model [171]. Uric acid was oxidized in the presence of micromolar concentrations of $\mathrm{PN}$ resulting in a previously unidentified uric acid derivative in human plasma [171]. This derivative resulted in endothelium-independent relaxation of rat aortic rings that was reversed by the administration of oxyhemoglobin, a NO scavenger [38, 59], or following administration of a cyclic GMP synthesis inhibitor [38, 40, 59, 172-174]. Endothelium-absent aortic ring segments displayed similar dose-response characteristics to the uric acid derivative when compared to endothelium-intact ring segments [171]. These results suggest that the NOdonating properties of the uric acid product are not mediated by NO release from the endothelium. NO release from the nitrated uric acid product was electrochemically confirmed and was not thiol-dependent [171], in contrast to the findings that organic nitrites release NO [66]. The authors suggested that uric acid is more susceptible to oxidation by PN than by other purines studied in this preparation (hypoxanthanine and xanthine), or in purine oxidation products (allantoin and parabanic acid) [171]. Finally, this uric acid nitration/nitrosation product may play a role in pathologic states by releasing NO, that can decrease vascular tone and increase tissue blood flow [171].

PN and hydrogen peroxide can generate hydroxyl radicals $[5,165,175]$, that produce tissue injury $[93,115,176-$ $178]$, and produce pronounced cerebral arteriolar dilation in low concentrations [80,82], as both radicals dilate cerebral arterioles by opening ATP-sensitive potassium channels [82]. Wei, Kontos et al. examined the roles of these radicals on vascular responses and how these radicals are modified by radical scavengers in a feline cranial window model [179]. The authors investigated the role of three antioxidants, dimethylsulfoxide (DMSO), salicylate, and L-cysteine, on cerebral arteriolar dilation following topical application of PN and hydrogen peroxide [179]. The effect of these antioxidants on the vasodilation caused by pinacidil and cromakalim, two known openers of ATP-sensitive potassium channels were examined [152, 180, 181]. The authors confirmed that PN and hydrogen peroxide produced cerebral arterial dilation by activation of potassium channels [82, 182] and that the responses were inhibited by the antioxidants [179]. However, the two water-soluble antioxidants, salicylate and L-cysteine, were more effective in inhibiting the vasodilatation from $\mathrm{PN}$ than that of hydrogen per-oxide, whereas the lipid-soluble agent, DMSO, was more effective in inhibiting the vasodilatation from hydrogen peroxide than $\mathrm{PN}$, and that all three antioxidants inhibited the responses in low concentrations. Their findings suggest that the sites of action for these two reactive oxygen species may be different, as cells are defended against superoxide by SOD and are defended against hydrogen peroxide by catalase and glu- 
tathione peroxidases [179]. Furthermore, these oxidants also inhibited responses to two potassium channel openers, pinacidil and cromakalim [179]. The variation in effectiveness of the antioxidants suggest that reactive species act at different sites, one in a water-soluble environment and the other in a lipid-soluble environment and can inhibit ATPsensitive potassium channels [179].

The formation and action of PN can be detected by measurement of nitrotyrosine residues [183]. In normal pregnancy, faint nitrotyrosine staining is found in the endothelium of placental villous tissue, whereas, in preeclampsia and/or intrauterine growth restriction, moderate to intense nitrotyrosine staining is seen in villous vascular endothelium, as well as in surrounding vascular smooth muscle and villous stroma [184]. The presence of nitrotyrosine residues, particularly in the endothelium, may indicate the formation and action of $\mathrm{PN}$, resulting in vascular damage that contributes to increased placental vascular resistance [184]. In preeclampsia, a major cause of maternal and fetal morbidity and mortality appears to be due to impaired vasodilator function and increased vasoconstrictor function due to disturbed endothelial barrier function [185]. Superoxide production is enhanced in pathologic processes $[37,46,186]$, and has been shown to interfere with the actions of NO [37, 46, 165]. In addition to toxic effects, PN may also act as an endogenous modulator of endothelial cell function [21, 23]. Okatani, Watanabe et al. evaluated the role of superoxide and of PN in regulating tone in the human fetoplacental vasculature [187]. In this study, helical sections of human umbilical arteries with intact endothelium were obtained from healthy pregnant women. Under increased tension conditions induced by potassium chloride, the authors demonstrated that superoxide is a potent vasoconstrictor, whereas $\mathrm{PN}$ is a vasodilator. The authors suggested that the vasorelaxation induced by exogenously PN in this model has biological relevance in the regulation of the human umbilical artery [187]. Subsequent studies in this model demonstrated that the administration of melatonin reduced the vasorelaxant properties of SIN-1, 3morpholinosydomine, a sydnonimine that is known to release superoxide and NO, and form PN under physiological conditions $[58,188]$. These authors suggested that melatonin significantly suppresses the vasorelaxant effect of SIN-1 due to the scavenging of PN [189].

Superoxide generated by oxidative stress in vascular disease can decrease endothelial-dependent vasorelaxation [1, 37, 135, 190, 191]. Moreover, prior studies may only assay the effects of vasorelaxants on one vascular bed with little to no comparison of the responses in multiple vascular beds from the same species. Pagano, Griswold et al. compared responses to SOD in multiple vascular beds in the rabbit, and to observe the capacities of these vascular beds to produce superoxide as well as NO, and finally, to observe the responses of the vascular beds to elevated levels of superoxide [192]. Using a lucigenin chemiluminescence assay, these authors found that baseline superoxide levels were higher in the carotid arteries than in the thoracic aorta, however, vasodilator responses to acetylcholine were not significantly different. Following treatment with a SOD inhibitor, superoxide levels were significantly higher in the carotid artery and in the abdominal aorta when compared to the thoracic aorta. The authors found that SOD inhibition would significantly reverse the endothelial-dependent response to acetylcholine in the thoracic aorta, but not in the carotid artery. Moreover, the SOD inhibition resistant relaxation to acetylcholine in the carotid artery was blocked by L-NAME, a NO synthase inhibitor. These results suggested that $\mathrm{PN}$, or possibly a superoxide resistant NO donor, is involved in carotid artery relaxation. Their findings suggested that a greater production of nitrite and of superoxide occurs in the carotid artery and that $\mathrm{PN}$ is the relaxing agent that is resistant to higher levels of superoxide in this artery, and suggests that $\mathrm{PN}$ is a superoxide resistant mediator [192].

Prior studies have shown that the relaxant effect of PN may be due to its oxidant properties, the nitrosylation of tissue thiols, or stimulation of cGMP production, and activation of ATP-sensitive potassium channels [22, 29, 163, 183, 193]. However, the differences observed among these studies may be related to different experimental protocols and species used in the studies. The mechanisms underlying PN induced vasodilation in isolated blood vessels was studied by $\mathrm{Li}, \mathrm{Li}$ et al., 2004, in an isolated canine cerebral arterial model [194]. Under basal conditions, PN $\left(10^{-10}\right.$ to $\left.10^{-6} \mathrm{M}\right)$ reduced ring tension in this preparation. Moreover, under elevated tone conditions, PN was able to elicit concentrationdependent relaxation with or without the presence of endothelium, with no significant differences observed in the response [199]. These data were in agreement with studies in other arterial ring preparations from different animals [23, $125,144]$, and are in agreement with the concept that the endothelium has no significant role in the modulation of PN responses [23]. However, these findings are in contrast to observations in a cerebral smooth muscle cell preparation and in middle cerebral arteries of the rat where PN induced contraction $[195,196]$. In this study, the PN-induced relaxation was reproducible without the development of tachyphylaxis, suggesting that the action of PN is reversible and does not cause vascular damage. The addition of methylene blue or of $1 \mathrm{H}$-[1,2,4] oxadiazolo-[4,3-alpha]quinoxalin-1-one (ODQ) to the ring preparations significantly reduced the relaxation induced by PN. The observation that methylene blue, a nonselective soluble guanylyl cyclase inhibitor $[21,34,38,45$, 54], or of ODQ, a specific soluble guanylyl cyclase inhibitor $[197,198]$, markedly inhibited the relaxations induced by PN suggest that action of PN is mediated through a cGMPdependent mechanism. The addition of calyculin $\mathrm{A}$ to the preparation abolished $\mathrm{PN}$-induced relaxation. The findings with calyculin A, which can inhibit myosin-light-chain phosphatase [199], suggests that activation of myosin phosphatase is an additional mechanism by which $\mathrm{PN}$ can induce relaxation in this preparation. In these experiments the authors found that tetraethylammonium chloride, a nonspecific potassium channel inhibitor, significantly decreased $\mathrm{PN}$-induced relaxations in a concentration-dependent manner, but that PN had no effect on rings that were precontracted by high concentrations of potassium chloride. These findings suggest that PN decreases muscle tone by activating potassium channels. Additionally, in this preparation, the authors examined the role of $\mathrm{Ca}^{++}$and observed that PN could reduce the magnitude of calcium-induced contractions of high $\mathrm{K}^{+}$-depolarized aortic rings in a concentration dependent manner. These findings suggest that PN may block the entry of extracellular calcium across the vascular smooth muscle membrane. In this series of experiments, the authors examined a role for NO-release and found that L-NMMA 
and L-NAME, two nonselective NOS inhibitors, or Larginine, a substrate for NO synthase, did not modulate PNinduced relaxation in this preparation. Finally, the effects of pharmacologic antagonists were examined in this study (diphenhydramine, cimetidine, methysergide, atropine, naloxone, and haloperidol), and it was found that none of the antagonists could influence $\mathrm{PN}$-induced relaxation. In regard to mechanisms, it was observed that $\mathrm{PN}$-induced relaxation in canine cerebral arteries is mediated by increases in cGMP, membrane hyperpolarization via potassium channel activation, activation of myosin light chain phosphatase, and interference with calcium entry and release [194].

The development of tachyphylaxis has been reported in some studies, but not in others [59, 61, 72, 75, 105, 194]. Additionally, PN has been reported to induce vasodilation by releasing vasoactive prostaglandins [200, 201]. Although PN causes vasodilation in a number of isolated arterial preparations [21, 23], the responses in the systemic and perfused hindquarters vascular beds and in the isolated perfused lung of the rat were not documented. We investigated the role of $\mathrm{PN}$ on vascular responses in these beds and observed that iv injections of PN produced dose-dependent decreases in hindquarters and systemic arterial pressure, whereas injections of PN into the lung perfusion circuit produced increases in pulmonary arterial pressure [202]. Moreover, responses to $\mathrm{PN}$ were rapid in onset, short in duration, and repeatable without exhibiting tachyphylaxis. Additionally, repeated injections of PN did not alter systemic, hindquarters, or pulmonary responses to endothelium-dependent vasodilators or to a number of vasoactive agonists that act by various mechanisms, and moreover, did not alter the hypoxic pulmonary vasoconstrictor response. Injections of sodium nitrate or nitrite or decomposed PN had little effect on vascular pressures. In these series of experiments responses to PN were not altered by the presence of meclofenamate, a nonselective cyclooxygenase inhibitor. These studies show that PN has significant pulmonary vasoconstrictor and hindquarters and systemic vasodepressor and vasodilator activities, and that repeated short-term exposure did not impair vascular responsiveness in these vascular beds, and finally that responses to $\mathrm{PN}$ are not dependent upon cyclooxygenase product release [202].

Studies have demonstrated that relaxation of feline cerebral arteries occurs upon topical administration of PN [82] and systemic administration of $\mathrm{PN}$ produce pronounced vasodilation in pentobarbital-anesthetized rats [154, 163, 203], and that this relaxation involves ATP-sensitive potassium channels [82, 154]. Moreover, tachyphylaxis develops following the administration of PN [59,72,154,163,203], and that the actions of a variety of $\mathrm{G}$ protein-coupled receptors agonists are substantially impaired [203]. These observed effects of PN upon $\mathrm{G}$ protein-coupled receptor-mediated responses may be related to functional amino acid residues on these proteins that are susceptible to oxidation or to nitration. Graves, Lewis et al., 2005 examined the role that progressive oxidation or nitration of amino acids within ATPsensitive potassium channels are responsible for the development of tachyphylaxis and that the loss of ATP-sensitive channel function may be due to agonist-induced activation of these channels [204]. Systemic injections of PN in the pentobarbital-anesthetized rat [154, 203], produced significant decreases in mean arterial pressure, and in mesenteric and hindquarters vascular resistances, with progressive development of tachyphylaxis to PN [204]. In subsequent series of experiments following the development of tachyphylaxis induced by ten injections of PN, responses to the ATPsensitive potassium channel agonist, cromakalim [152, 179], were reduced, whereas to sodium nitroprusside responses were unchanged. These findings suggest that the development of tachyphylaxis to PN involve the loss of ATPsensitive potassium channel function that may be due to oxidation or nitration of amino acids found in these channels [204].

The vasorelaxant action of PN has many characteristics in common with NO [61], and this action may be due to oxidation or nitration of amino acids, nitrosylation of tissue thiols, or the stimulation of cGMP production and activation of ATP-sensitive potassium channels [22, 29, 163, 183, 204]. Prior studies in canine cerebral arteries demonstrated that the vasodilator effects of PN are mediated by elevation of cGMP levels, membrane hyperpolarization via potassium channel activation, activation of myosin-light-chain phosphatase, and interference with calcium entry [194]. However, the presence of these PN pathways in other blood vessels, such as the aorta is unknown. Li, Li et al., 2005 evaluated the effects of $\mathrm{PN}$ in isolated rat aorta segments and under baseline tone conditions, $\mathrm{PN}$ failed to alter tension in the aortic rings [205]. However following contraction with phenylephrine, PN elicited concentration-dependent relaxations. No significant differences in relaxation were found in either endothelium-present or endothelium-absent rings. The addition of methylene blue or ODQ reduced relaxation induced by PN, whereas sildenafil significantly potentiated PN induced relaxation. The addition of tetraethylammonium chloride also significantly decreased relaxation induced by $\mathrm{PN}$ in a concentration-dependent manner. PN had no significant effect on rings precontracted with high potassium chloride solution. The addition of calyculin A significantly reduced PN mediated relaxation in a dose dependent manner, and PN significantly reduced calcium-induced contractions in potassium depolarized aortic rings. Finally, a variety of pharmacologic agonists and antagonists including L-NMMA, L-arginine, indomethacin, atropine, naloxone, diphenhydramine, cimetidine, glibenclamide, haloperidol, SOD, and catalase did not influence the relaxant responses to $\mathrm{PN}$ in this preparation. These finding suggest that $\mathrm{PN}$-induced relaxation of rat aortic rings are mediated by elevations in cGMP levels, membrane hyperpolarization via potassium-channel activation, activation of myosin phosphatase activity, and interference with calcium entry [205]. These results confirm earlier studies in canine cerebral arteries and suggest that these mechanisms are found in several vascular beds and in different species [194].

Although the mechanism by which PN alters ATPsensitive channels is not understood [82, 154], it is unlikely that the oxidant properties of PN are involved since oxidants have been shown to reduce ATP-sensitive potassium channel activity [206, 207]. Moreover, PN mediate vasodilator responses have been shown to be markedly attenuated by the ATP-sensitive potassium channel blocker, glibenclamide [208], but are not attenuated by L-penicillamine, in doses that can reduce the vasodilator responses to L-Snitrosocysteine, a S-nitrosothiol [163]. Graves, Kooy et al. 2006 [209] examined the role of L-penicillamine in the re- 
sponses to PN in their pentobarbital-anaesthetized rat model $[72,75]$. These authors found that although the initial reductions in mean arterial pressure and in systemic and hindquarters vascular resistances elicited by PN were not decreased by L-penicillamine, the responses were much shorter in duration. Although the ATP-sensitive potassium channel agonist, cromakalim, decreased mean arterial pressure and vascular resistance; these responses were not modulated by Lpenicillamine, suggesting this PN scavenger is not a nonselective inhibitor. These findings that the vasodilator actions of PN were markedly attenuated by ATP-sensitive potassium channel blocker, glibenclamide [208], led these authors to suggest that PN can dilate resistance arteries by ATPsensitive potassium channel dependent and ATP-sensitive potassium channel independent mechanisms. Although PN may initiate vasodilation by formation of S-nitrosothiols; the sustained vasodilation is maintained by the activation of ATP-sensitive potassium channels [209]. Finally their findings found that L-penicillamine can scavenge PN and interfere with the PN-mediated vasodilator mechanisms [209].

In studies in isolated rat pulmonary artery rings, in isolated rat aortic rings, in feline coronary artery rings, or in rat pulmonary and systemic circulations, vasorelaxant responses to acetylcholine were not inhibited following exposure to PN, and tachyphylaxis to the vasorelaxant response to $\mathrm{PN}$ was not reported, and in one preparation, responses to acetylcholine were enhanced $[25,105,125]$. However, responses in other vascular beds of the cat are not well described, that led this laboratory to investigate responses of PN in the hindlimb vascular bed of the cat [202, 210]. Injections of PN into the perfusion circuit caused dose-dependent decreases in perfusion pressure. Inasmuch as blood flow was maintained constant, the decreases in perfusion pressure reflect decreases in hindlimb vascular resistance. The hindlimb vasodilator responses to PN were rapid in onset, short in duration, and the vasodilator responses to PN could be repeated without causing tachyphylaxis [210]. The absence of the development of tachyphylaxis to the vasodilator response to $\mathrm{PN}$ is in agreement with studies in the systemic and hindlimb vascular bed of the rat, and in isolated coronary arteries from the dog and cat $[23,25,202]$. Although PN has been reported to produce vascular dysfunction, the results of these studies observed that vascular responses of $\mathrm{PN}$ to could be repeated as subsequent injections, in doses up to $4000 \mathrm{nmol}$, had no significant effect on baseline perfusion pressure or on responses to vasoactive agonists [210]. Moreover, repeated short-term exposure to PN had no significant effect on vasodilator responses to acetylcholine, sodium nitroprusside, DEA/NO, or to albuterol. These data suggest that PN does not impair endothelial function in the hindlimb vascular bed. The results showing that vasodilator responses to acetylcholine are not inhibited are consistent with results in the hindquarters vascular bed or in aortic rings of the rat, in isolated cat coronary arteries, and in isolated rat pulmonary arteries where responses to acetylcholine were enhanced by the highest dose of PN studied $[25,105,125$, 202]. These data are in contrast to studies showing that responses to vasodilator agents, including acetylcholine, are reduced after the development of tachyphylaxis to PN [59, 154]. The explanation for differences in results is uncertain, but may be explained by the observation that in studies where responses to acetylcholine were preserved, tachyphylaxis to PN was not observed $[25,105,125,202]$. The repeated ad- ministration of $\mathrm{PN}$ did not alter vasoconstrictor responses to norepinephrine, U46619, or angiotensin II in the hindlimb vascular bed. These data are in contrast to studies in the anesthetized rat where regional vascular responses to iv injections or exposure to several catecholamines was reduced following systemic administration of PN $[125,203]$. The reason for the difference in results is uncertain, but may involve the route of administration used. The results in the hindlimb vascular bed of the cat indicate that PN does not impair alpha- or betaadrenergic, thromboxane A2, or angiotensin II receptor mediated responses or impair endothelial function under the conditions of these experiments [210]. The mechanism by which PN produces a vasodilator response in the hindlimb circulation was investigated and the role of NO synthase was examined. The role of NO synthase/soluble guanylate cyclase/cGMP dependent pathway in the vasorelaxant properties of PN has been investigated in a number of vascular preparations [21, 23]. However, studies attempting to investigate the role of soluble guanylate cyclase have been hampered by the lack of a potent and selective inhibitor of this enzyme in in vivo preparations. Methylene blue has been used but this compound is not selective [211]. However, information involving this pathway can be inferred with the use of selective guanylate or G-kinase inhibitors [212-217]. Our findings with the type 5 cGMP phosphodiesterase inhibitor on responses to PN and the two NO donors, suggest that our observations are in agreement with other studies in that PN acts by a NO-cGMP dependent mechanism $[21,194,205]$. These findings are in contrast with other studies reporting that the NO-cGMP pathway does not play a role, but rather the PARS pathway mediates the vasoactive properties of PN [105]. These results show that responses to PN were not altered by L-NAME in a dose that attenuated vasodilator responses to acetylcholine. These data suggest that responses to PN are not mediated by release of NO from the endothelium. The cyclooxygenase inhibitor, sodium meclofenamate, had no significant effect on the response to $\mathrm{PN}$ in a dose that attenuated responses to the prostaglandin precursor, arachidonic acid, suggesting that responses to PN are not dependent on the release of vasodilator products in the cyclooxygenase pathway. It has been reported that decreases in systemic arterial pressure and regional vascular resistance in response to PN are mediated by ATP-sensitive potassium channels and that tolerance to PN involves ATP-sensitive potassium channels in the anesthetized rat [208]. In the present study in the cat hindlimb vascular bed, vasodilator responses to PN were not inhibited by the $\mathrm{K}^{+}$-ATP channel antagonist, U37883A, in a dose that attenuated responses to the $\mathrm{K}^{+}$-ATP channel opener, levcromakalim. These data are in agreement with studies in precontracted rat aortic rings where glybenclamide did not influence the relaxant effects of PN, but are in contrast to studies showing that glybenclamide reduced vasodilator responses to $\mathrm{PN}$ in the rat $[208,218]$. The explanation for the differences in results is uncertain, but again may involve route of administration, species, or vascular bed studied. The observation that the vasodilator responses to $\mathrm{PN}$ in the cerebral vascular bed of the cat with a cranial window was attenuated by glybenclamide suggest that the mechanism of the vasodilatory response may depend upon the vascular bed studied in the cat [82]. It has been reported that vasorelaxant responses to $\mathrm{PN}$ are dependent on the formation of $\mathrm{NO}$ donorlike compounds [21, 61, 219]. The reaction of PN with thiol groups on plasma proteins, sugars, and tissue substituents can 
result in the rapid formation of an S-nitrosothiol NO donor compound that has vasodilator properties [61, 125, 219]. It has been hypothesized that the involvement of nitrosothiols which release NO can serve to prolong vasodilator responses to NO $[21,220,221]$. It has been reported that relaxation of isolated arterial segments in response to $\mathrm{PN}$ is mediated by the release of NO from an S-nitrosothiol, the activation of soluble guanylate cyclase, and the accumulation of cGMP in vascular tissue [21, 194, 205]. The role of S-nitrosothiol formation has been questioned and in other studies evidence has been presented to show that PN induced vasodilation is not mediated by the formation of S-nitrosothiols [82, 163]. However, the present studies do not provide information on the identity or chemical nature of the species formed from PN, but do provide information on the mechanism of the vasodilator response to PN. Although it is technically difficult to measure cGMP levels in resistance vessels in the hindlimb vascular bed of the cat or rat, the hypothesis that a cGMP dependent mechanism is involved can be investigated by the use of a type 5 cGMP phosphodiesterase inhibitor [213, 214]. In these experiments, the effects of zaprinast, a type 5 cGMP phosphodiesterase inhibitor, on responses to PN and several NO donors were investigated. These results show the hindlimb vasodilator responses to $\mathrm{PN}$, and to the NO donors, sodium nitroprusside and DEA/NO, were enhanced in duration at a time when vasodilator responses to the beta 2 receptor agonist, albuterol, were not altered. These data along with the observation that the type 4 cAMP phosphodiesterase inhibitor, rolipram, did not alter the duration of the response to $\mathrm{PN}$, provides evidence in support of the hypothesis that PN induced vasodilation in the cat circulation is mediated, at least, in part by a cGMP-dependent mechanism [222, 223]. Although experiments with zaprinast provide evidence in support of a cGMP dependent mechanism, additional support for this mechanism could be derived from experiments with inhibitors of guanylate cyclase and of cGMP dependent protein kinase. However, such agents are not currently available for use in the intact cat preparation [210].

\section{ANTI-PLATELET AGGREGATION EFFECTS OF PEROXYNITRITE}

Alterations in the bioavailability of endothelium-derived factors play a role in the early course of vascular diseases [224]. As endothelial dysfunction occurs early [225], and subsequently heralds pathologic changes in vascular structure and activation of platelets and leukocytes, these events lead to the development of atherosclerosis and thrombosis [226]. NO has been shown to inhibit platelet aggregation and vessel adhesion [1, 227], whereas superoxide reduces antiplatelet activities of NO [37]. PN is a cytotoxic molecule in inflammatory conditions [104], but the role of this downstream molecule to $\mathrm{NO}$ and superoxide had not been fully evaluated on platelet function. Moro, Darley-Usmar et al. 1994 investigated the role of this oxidant in suspensions of washed platelets and also in platelet-rich plasma obtained from human subjects [22]. These authors observed that PN $(20 \mu \mathrm{M}-200 \mu \mathrm{M})$, but not of decomposed PN, when added to washed platelet suspensions produced concentration-dependent increases in aggregation when measured by platelet- ionized calcium aggregometer [22]. The additions of platelet aggregation inhibitors such as SNAP, prostacyclin, or indomethacin $[228,229]$ to the washed platelet suspensions had no significant effect on platelet aggregation induced by PN [22]. The addition of PN could also completely reverse the inhibitory effects of SNAP on collagen-induced platelet aggregation, whereas PN would significantly reverse $(\sim 50 \%)$ the antiaggregatory effects of indomethacin and of prostacyclin [22]. These results suggested that PN could counteract the platelet-inhibitory effects induced by stimulation of cGMP, cAMP, or by inhibition of thromboxane formation [22]. Moreover, the addition of catalase, superoxide dismutase, mannitol, desferrioxamine, or DTPA to the washed platelet suspensions had no effect on platelet aggregation induced by PN [22]. These results suggest that PN has a direct effect on platelets not due to the formation of hydrogen peroxide, superoxide, or hydroxyl radicals. In contrast, the addition of EGTA or RGDS to the washed platelet suspension completely inhibited PN-induced aggregation [22]. These findings that the proaggregatory action of PN can be prevented by RGDS, a IIb/IIIa receptor antagonist, or by EGTA, a calcium-chelating agent that can interfere with exposure of this IIb/IIIa receptor, suggest that PN induces platelet aggregation by directly stimulating platelet receptors [22]. However, these findings of PN-induced aggregation on washed platelets were in contrast to the effects of PN in platelet-rich plasma, where PN $(20 \mu \mathrm{M}-200 \mu \mathrm{M})$ acted as an inhibitor of platelet aggregation, and inhibited collageninduced aggregation in platelet-rich plasma [22]. This novel effect of PN could be reversed by prior incubation with hemoglobin suggesting a role for NO formation. The first observation of the inhibitory effect of NO and NO donors on platelet aggregation was made in 1983 [230]. The addition of platelet poor plasma to washed platelets resulted in PN inhibition of platelet aggregation [22]. Moreover, reversal of the aggregatory effect of PN is observed in washed platelets following the additions of low concentrations of human serum albumin, or GSH, but this effect was not seen in the presence of oxidized glutathione (GSSH) [22]. Following the addition of GSH to solutions of PN, significant amounts of $\mathrm{NO}$ and S-nitrosoglutathione were detected by chemoluminescence. These findings suggest that PN can be modified and that plasma thiols are candidates since they counteract the actions of oxidants $[112,231]$. NO and GSNO are formed in the reaction between PN and GSH with the formation of GSNO involving the hemolytic cleavage of PN yielding nitrites which can nitrosylate thiols [232]. These authors concluded that the actions of PN may be dependent upon the pathologic state and that thiols exert their protective actions by these mechanisms [22]. Moro, Darley-Usmar et al. 1995 further investigated the products of the reaction between Dglucose and PN on platelet inhibition [61], and found greater inhibition of aggregation when compared to PN alone, and that the platelet inhibition was dependent on the concentration of D-glucose [61]. Moreover, when L-glucose was substituted for D-glucose, the platelet inhibition were equally effective, and that these effects were reversed by oxyhemoglobin [61].

Platelet aggregation is inhibited by NO, which binds to the heme of platelet guanylate cyclase that increases cGMP 
Table 1. Studies Examining the Vasomotor Properties of PN

\begin{tabular}{|c|c|c|c|c|}
\hline Authors & Model & PN Concentrations & Findings & Reference \\
\hline Liu, Beckman et al. & $\begin{array}{l}\text { Isolated canine coronary artery } \\
\text { rings precontracted with PGF2a }\end{array}$ & $10 \mathrm{nM}$ to $30 \mu \mathrm{M}$ & $\begin{array}{l}\text { Vasodilation regardless of the presence of the } \\
\text { endothelium } \\
\text { PN was } 7 \text { - to } 10 \text {-fold less potent than NO } \\
\text { Tachyphylaxis was not observed }\end{array}$ & [23] \\
\hline Wu, Pritchard et al. & $\begin{array}{l}\text { Isolated bovine pulmonary arterial } \\
\text { smooth muscle rings, potassium- } \\
\text { preconstricted } \\
\text { Endothelium-intact preparations } \\
\text { incubated for } 30 \text { min with a high } \\
\text { concentration of PN }\end{array}$ & $0.1 \mu \mathrm{M}$ & $\begin{array}{l}\text { Vasodilation regardless of the presence of the } \\
\text { endothelium } \\
\text { Incubation with PN did not significantly alter } \\
\text { relaxation responses to acetylcholine }\end{array}$ & [21] \\
\hline Villa, Salas et al. & Isolated perfused rat heart & $\begin{array}{l}0.3 \mu \mathrm{M} \text { to } 1000 \mu \mathrm{M}, \\
\text { single-dose infusions } \\
30-100 \mu \mathrm{M}\end{array}$ & $\begin{array}{l}\text { Dose-dependent vasodilation of coronary } \\
\text { vascular bed } \\
\text { Development of tachyphylaxis in response to } \\
3 \text { to } 4 \text { repeated infusions }\end{array}$ & [59] \\
\hline $\begin{array}{l}\text { Moro, Darley- } \\
\text { Usmar et al. }\end{array}$ & $\begin{array}{l}\text { Isolated rabbit aortic strips de- } \\
\text { nuded of endothelium \& super- } \\
\text { fused in a cascade bioassay }\end{array}$ & $30-300 \mu \mathrm{M}$ & $\begin{array}{l}\text { Vasodilation } \\
\text { No observed tachyphylaxis } \\
\text { Reacts with organic molecules to form an NO } \\
\text { donor }\end{array}$ & [61] \\
\hline $\begin{array}{l}\text { Holcberg, Kossen- } \\
\text { jans et al. }\end{array}$ & $\begin{array}{l}\text { Isolated perfused human placental } \\
\text { cotyledons preconstricted with the } \\
\text { thromboxane agonist, U46619 }\end{array}$ & $\begin{array}{l}\text { PN precursor, superox- } \\
\text { ide } 0.53 \mu \mathrm{M} / \mathrm{L} \text { infusion } \\
\text { combined with NO } \\
\text { infusion }\end{array}$ & $\begin{array}{l}\text { Greater vasodilatation observed with combina- } \\
\text { tion when compared to an infusion of NO } \\
\text { alone }\end{array}$ & [69] \\
\hline Kooy, Royall et al. & $\begin{array}{l}\text { Mesenteric, renal, and hindquar- } \\
\text { ters blood flow velocity in the rat }\end{array}$ & $10 \mu \mathrm{M} / \mathrm{kg}$ & $\begin{array}{l}\text { Initial vasodilation seen in mesenteric and } \\
\text { hindquarters beds, but rapid development of } \\
\text { tachyphylaxis with repeated administration } \\
\text { Attenuation of responses to catecholamines } \\
\text { following the development of tachyphylaxis to } \\
\text { PN }\end{array}$ & [72] \\
\hline Kooy \& Lewis & $\begin{array}{l}\text { Mesenteric, renal, and hindquar- } \\
\text { ters blood flow velocity rat in the } \\
\text { rat }\end{array}$ & $10 \mu \mathrm{M} / \mathrm{kg}$ & $\begin{array}{l}\text { Significant decreases in hindquarters and mes- } \\
\text { enteric resistance, but with minor decreases in } \\
\text { renal resistance } \\
\text { Development of a sustained increase in mean } \\
\text { arterial pressure and in vascular resistance, } \\
\text { following PN exposure }\end{array}$ & [75] \\
\hline Wei, Kontos et al. & $\begin{array}{l}\text { Cerebral arterioles of the anesthe- } \\
\text { tized cat with cranial windows }\end{array}$ & $1,3,5 \mu \mathrm{M}$ & $\begin{array}{l}\text { Dose-dependent vasodilation } \\
\text { Glyburide inhibited the vasodilator response to } \\
\text { hydrogen peroxide or PN }\end{array}$ & [82] \\
\hline Lefer, Scalia et al. & Isolated rat aortic rings & $\begin{array}{l}\text { 1) } 5 \mu \mathrm{M} \\
\text { 2) } 50 \mathrm{nM}-500 \mathrm{nM}\end{array}$ & $\begin{array}{l}\text { 1) Significant relaxation } \\
\text { 2) No detectable effect } \\
\text { Macromolar range exerts significant vasore- } \\
\text { laxant effects } \\
\text { Does not impair endothelium dependent re- } \\
\text { sponses }\end{array}$ & [26] \\
\hline $\begin{array}{l}\text { Chabot, Mitchell } \\
\text { et al. }\end{array}$ & $\begin{array}{l}\text { Isolated pulmonary arterial ring } \\
\text { preparation under elevated tone } \\
\text { conditions following contraction } \\
\text { with the potent thromboxane mi- } \\
\text { metic, U46619 }\end{array}$ & $10 \mathrm{nM}$ to $100 \mu \mathrm{M}$ & $\begin{array}{l}\text { Vasorelaxation } \\
\text { PN augmented the relaxations induced by the } \\
\text { endothelium-dependent vasodilator, acetylcho- } \\
\text { line } \\
\text { PARS inhibition significantly reduced the } \\
\text { relaxation responses to PN }\end{array}$ & {$[105]$} \\
\hline Dowell and Martin & $\begin{array}{l}\text { Isolated rat aortic rings, under } \\
\text { elevated tone conditions }\end{array}$ & $1 \mu \mathrm{M}-100 \mu \mathrm{M}$ & $\begin{array}{l}\text { Dose-dependent relaxation } \\
\text { No development of tachyphylaxis } \\
\text { No significant long-term modulation of phen- } \\
\text { ylephrine-induced contraction by PN } \\
\text { PN can react with glucose and other com- } \\
\text { pounds with functional alcohol groups to form } \\
\text { vasorelaxant species }\end{array}$ & {$[125]$} \\
\hline
\end{tabular}




\begin{tabular}{|c|c|c|c|c|}
\hline Authors & Model & PN Concentrations & Findings & $\begin{array}{l}\text { able 1) contd. } \\
\text { Reference }\end{array}$ \\
\hline Dowell and Martin & $\begin{array}{l}\text { Isolated endothelium-denuded rat } \\
\text { aortic rings, preconstricted with } \\
\text { phenylephrine }\end{array}$ & $1 \mu \mathrm{M}$ & $\begin{array}{l}\text { Profound depression of phenylephrine-induced } \\
\text { contraction } \\
\text { No effect on long-term depression of endothe- } \\
\text { lial-induced vasoconstriction } \\
\text { Analogues containing free thiols are necessary } \\
\text { for the formation of NO-releasing compounds }\end{array}$ & {$[144]$} \\
\hline $\begin{array}{l}\text { Graves, Lewis et } \\
\text { al., } 1998\end{array}$ & $\begin{array}{l}\text { Mesenteric, renal, and hindquar- } \\
\text { ters flow velocity rat model }\end{array}$ & $0.5 \mu \mathrm{M}-10 \mu \mathrm{M}$ & $\begin{array}{l}\text { Dose-dependent decreases in mean aortic } \\
\text { pressure and in hindquarters and mesenteric } \\
\text { resistance } \\
\text { S-nitrosothiols are unlikely to be primarily } \\
\text { responsible for the hemodynamic effects of PN }\end{array}$ & {$[163]$} \\
\hline $\begin{array}{l}\text { Skinner, White et } \\
\text { al. }\end{array}$ & Isolated aortic ring rat model & 0.05 to $1 \mathrm{mM}$ & $\begin{array}{l}\text { Dose-dependent relaxation } \\
\text { Uric acid derivative from PN and albumin } \\
\text { resulted in endothelium-independent relaxation }\end{array}$ & {$[171]$} \\
\hline Wei, Kontos et al. & Feline cranial window model & 0.5 to $5 \mu \mathrm{M}$ & $\begin{array}{l}\text { Dose-dependent relaxation } \\
\text { Water-soluble antioxidants are more effective } \\
\text { in PN inhibition }\end{array}$ & [179] \\
\hline Li, Li et al., 2004 & $\begin{array}{l}\text { Isolated canine cerebral arterial } \\
\text { rings model, baseline tone and } \\
\text { preconstricted with PGF2a }\end{array}$ & $10^{-10}$ to $10^{-6} \mathrm{M}$ & $\begin{array}{l}\text { Dose-dependent relaxation with or without } \\
\text { endothelium } \\
\text { Endothelium has no significant role in the } \\
\text { modulation of PN responses } \\
\text { Activation of myosin phosphatase } \\
\text { May block the entry of extracellular calcium } \\
\text { across vascular smooth muscle membranes }\end{array}$ & {$[194]$} \\
\hline $\begin{array}{l}\text { Graves, Lewis et al. } \\
2005\end{array}$ & $\begin{array}{l}\text { Mesenteric, renal, and hindquar- } \\
\text { ters blood flow velocity rat model }\end{array}$ & $10 \mu \mathrm{M} / \mathrm{kg}$ & $\begin{array}{l}\text { Development of tachyphylaxis involves the } \\
\text { loss of ATP-sensitive potassium channel func- } \\
\text { tion }\end{array}$ & [204] \\
\hline Li, Li et al., 2005 & Isolated rat aorta rings model & $10^{-8}$ to $10^{-4} \mathrm{M}$ & $\begin{array}{l}\text { Dose-dependent relaxation } \\
\text { Mediated by elevations in cGMP levels, mem- } \\
\text { brane hyperpolarization via potassium-channel } \\
\text { activation, activation of myosin phosphatase } \\
\text { activity, and interference with calcium move- } \\
\text { ment and calcium entry }\end{array}$ & {$[205]$} \\
\hline $\begin{array}{l}\text { Graves, Kooy et al. } \\
2006\end{array}$ & $\begin{array}{l}\text { Mesenteric, renal, and hindquar- } \\
\text { ters blood flow velocity rat model }\end{array}$ & 1 to $20 \mu \mathrm{M} / \mathrm{kg}$ & $\begin{array}{l}\text { Dilates resistance arteries by ATP-sensitive } \\
\text { potassium channel dependent and ATP- } \\
\text { sensitive potassium channel independent } \\
\text { mechanisms }\end{array}$ & [209] \\
\hline $\begin{array}{l}\text { Nossaman, Bi- } \\
\text { valacqua et al. }\end{array}$ & Hindlimb vascular bed of the cat & 400 to $4000 \mathrm{nM}$ & $\begin{array}{l}\text { Vasodilator response not inhibited by } \mathrm{K}^{+} \text {ATP } \\
\text { channel blocker } \\
\text { Response mediated by a cGuP-dependent } \\
\text { mechanism } \\
\text { No impairment of endothelial function } \\
\text { Repeated administration did not alter responses } \\
\text { to norepinephrine, U46619, or angiotensin II }\end{array}$ & [210] \\
\hline
\end{tabular}


formation and inhibits platelet activation [233]. Hydrogen peroxide is a weak activator of platelets [234], and may be formed when platelets are activated [235, 236]. Although PN has recently been shown to induce both platelet-stimulatory and -inhibitory effects $[22,61]$, and that both hydrogen peroxide and PN are formed under inflammatory conditions [237], the role of hydrogen peroxide and PN on platelet function are uncertain. Naseem and Bruckdorfer investigated this combination of radicals in platelet-rich plasma obtained from healthy human volunteers [238]. The addition of physiologically relevant concentrations of hydrogen peroxide did not inhibit thrombin or collagen-induced platelet aggregation, whereas the addition of NO was effective [238]. However, the simultaneous administration of $\mathrm{NO}$ and hydrogen peroxide to this suspension inhibited the agonist-induced aggregation that was greater than the inhibition caused by NO alone [238]. The addition of the NO scavenger, carboxyPTIO [239], resulted in complete reversal of NO-induced inhibition of aggregation, even when hydrogen peroxide was simultaneously added with NO [238]. These findings suggest that there is enhanced NO platelet sensitivity in the presence of hydrogen peroxide, but that the inhibitory activity was dependent upon $\mathrm{NO}$ and suggest that hydrogen peroxide may have a positive role in the amplification of the action of NO [238].

The earlier reports by Moro, Darley-Usmar et al. 1994, 1995 demonstrated that PN could affect platelet aggregation under different experimental conditions, platelet-rich plasma and washed platelet suspensions, but were investigated with the use of one aggregating agent, collagen [22, 61]. Prior investigations $[5,21-23,240]$ with $\mathrm{PN}$ were undertaken with $\mathrm{PN}$ synthesized from $\mathrm{NaNO} 2$ and $\mathrm{H} 2 \mathrm{O} 2$ in an acid medium, with the resultant mixture containing contaminants that could alter experimental results. To further study the effects of PN on platelet aggregation in different media and to observe the effects of PN in the presence of more conventional platelet activators, Yin, Lai et al. examined the role of PN using a synthesis process that was free of $\mathrm{H} 2 \mathrm{O} 2$ and $\mathrm{NaNO} 2$, on platelet-rich plasma, platelet-poor plasma, and with albumin obtained from human volunteers [241]. Increasing concentrations of PN $(50 \mu \mathrm{M}-200 \mu \mathrm{M})$ added to the presence of different platelet aggregation inducing agents, such as ADP, collagen, thrombin, and U46619, inhibited platelet aggregation in a dose-dependent manner [241]. Moreover, the authors observed that the addition of PN could reverse platelet aggregation previously induced by collagen, ADP and thrombin. These findings suggest that PN nitrosylates plasma proteins [241] that prevents phosphorylation of tyrosine residues needed for calcium influx or mobilization necessary for platelet aggregation [242]. As PN is a potent tyrosine nitrating agent [183], and that elevated levels of nitrotyrosine have been observed in inflammatory states [243], it is possible that PN induces nitration of tyrosine that blocks tyrosine phosphorylation and results in the inhibition of the primary phase of aggregation [241]. The anti-aggregatory effects of PN were dependent upon the presence of nitrite mixed with PN as complete inhibition of ADP-induced platelet aggregation was obtained with a lower dose of PN formulated with nitrite contamination when compared to the nitrite-free PN preparation [241]. However, PN that had been preincubated with either platelet-poor plasma or with albumin did not alter inhibition of aggregation when added to platelet-rich plasma and were comparable to results with PN under initial experimental conditions. These latter findings suggest that PN inhibition of aggregation required protein nitrosylation [241] and not the release of NO as suggested by other studies $[5,21]$ and are supported by the observation that intracellular cGMP levels are only increased at the highest concentration $(200 \mu \mathrm{M})$ of $\mathrm{PN}$ studied in this preparation [241].

Nitrosative stress and PN can generate NO donors [21, $22,61]$. These findings as well as other studies [25, 26], suggest that PN can exert a cytoprotective function, whereas PN oxidative stress worsens pathologic conditions [244-246]. Certainly, the imbalance between NO and superoxide has been implicated in inflammatory disease states [57, 165, 247-249]. PN can promote aggregation of platelets [22], however in the presence of low concentrations of plasma, PN can inhibit this aggregation [241]. PN may nitrate tyrosine residues in platelet proteins and interfere with platelet aggregation [250], whereas PN can also induce platelet aggregation $[22,61,241,251]$. These studies as well as others suggest that PN can participate in both nitrosative and oxidative stress $[63,252]$. Previous studies are unclear about the role of P-selectin in the aggregation of platelets [22,61], and in some studies of platelet activation, P-selectin expression were decreased in the presence of PN [250]. P-selectin is an adhesion glycoprotein found on platelets and is rapidly expressed following platelet activation or by activated endothelium [253]. These dual actions of PN were investigated by Brown, Moro et al. on washed platelets and in human platelet-poor plasma by examining P-selectin expression, platelet calcium concentrations, and aggregation in platelets [254]. These authors observed that PN $(50 \mu \mathrm{M}-400 \mu \mathrm{M})$, but not decomposed PN, produced concentration-dependent increases in platelet P-selectin expression, and increases in platelet $\mathrm{Ca}^{++}$concentration [254]. The results in washed platelets indicate that PN induces aggregation by mobilization of $\mathrm{Ca}^{++}$from the extracellular compartment, as shown in earlier studies that pro-aggregatory effects of PN were inhibited by EGTA, a $\mathrm{Ca}^{++}$chelating agent [22]. In contrast, PN $(50 \mu \mathrm{M}-400 \mu \mathrm{M})$, but not decomposed PN, inhibited collagen-induced P-selectin expression and when platelet-poor plasma was added to PN, the inhibition was further enhanced [254]. These data suggest PN produces a mediator that is capable of inhibiting P-selectin expression in platelets. The role of endogenous $\mathrm{NO}$ on the inhibitory effects of PN was examined, and preincubated washed platelets with the soluble guanylate cyclase inhibitor, ODQ [197,198,254], or with the NO scavenger, oxyhemoglobin [254]. In the presence of ODQ, PN-induced P-selectin expression was enhanced 2- to 3 -fold achieving maximal activation in washed platelets, and ODQ reversed PN inhibition of collagen-induced P-selectin up-regulation [254]. In contrast, oxyhemoglobin, reversed PN-induced inhibition of collagen-induced aggregation. The data that collagen-induced P-selectin expression was sensitive to oxyhemoglobin or ODQ suggest activation of NOsoluble guanylate cyclase is important in modulating platelet aggregation [254]. PN has dual effects on platelets due to the conversion to NO or NO donors. PN $(100 \mu \mathrm{M}-3000 \mu \mathrm{M})$ produced a concentration-dependent depletion of platelet membrane thiols, but at concentrations higher than associated with the release of NO or a NO donor [254]. PNinduced platelet activation seems to be dependent upon thiol 
oxidation and an increase in intracellular $\mathrm{Ca}^{++}$. To investigate the actions of thiol oxidation, washed platelets were preloaded with the fluorescent $\mathrm{Ca}^{++}$-sensitive probe, FURA2 , then washed and treated with PN. PN $(200 \mu \mathrm{M}-400 \mu \mathrm{M})$ produced a concentration-dependent increase in intracellular calcium levels, that only became significant at $300 \mu \mathrm{M}$ or above [254]. These data suggest that PN can exert dual effects on platelets, activation or inhibition depending upon the conditions. PN-induced platelet activation seems to be dependent upon thiol oxidation and increase in intracellular $\mathrm{Ca}^{++}$, whereas the inhibitory effects of $\mathrm{PN}$ is dependent upon the conversion to NO or a NO donor [254]. The inhibitory NO-dependent effects of PN occur at lower concentrations than the activating effects. The authors concluded that these observations are in agreement with other studies showing both damaging (activating) and cytoprotective (inhibiting) effects [254].

$\mathrm{PN}$ or PN-generating systems induce nitration of tyrosine residues in proteins via intermediate formation of tyrosyl radicals and nitrite [255]. Studies have shown repeated exposure of platelets to PN increase levels of nitration [250]. Moreover, the generation of tyrosyl radicals is a critical first step in the formation of thromboxane A2, a potent lipid mediator of platelet activation $[234,241]$. As the effects of PN on COX protein nitration and on prostaglandin formation in platelets have not been investigated, Boulos, Jiang et al. investigated these effects in washed platelet suspensions obtained from human volunteers [256]. These authors observed that PN $(100 \mu \mathrm{M}-190 \mu \mathrm{M})$ would produce a moderate aggregatory effect, which was less than the effect obtained with arachidonic acid. However, treatment with lower PN concentrations $(4 \mu \mathrm{M}-50 \mu \mathrm{M})$ inhibited arachidonate-induced aggregation in a dose-dependent manner [256]. Preincubation with a polyphenolic tea antioxidant that inhibits tyrosine nitration [257], significantly reduced the inhibitory effect of $\mathrm{PN}$ on arachidonate-induced platelet aggregation. The exposure of COX-1 and COX-2 to PN generated COX proteins that were immunoreactive to 3-nitrotyrosine antibodies [256]. COX-1 and COX-2 contain 27 tyrosine residues, suggesting that PN nitration of COX is likely to impair formation of tyrosyl radicals necessary for enzymatic activity [256]. In contrast, PN stimulated prostaglandin biosynthesis when added to arachidonic acid and increased PGH2 levels or peroxide tone required for eicosanoid signaling. These results suggest that $\mathrm{PN}$ targets both $\mathrm{COX}$ and arachidonic acid and modulates eicosanoid synthesis. Reactive species are often generated in inflammatory conditions and the timing of these events is important in predicting the net effect of PN on platelets [256].

PN oxidizes sulfhydryl groups and induces membrane lipid peroxidation in the arterial wall [57, 188], and stimulates nitration or nitrosation leading to impaired cellular function and alteration in signaling pathways [191, 258-261]. Nowak and Wachowicz studied the actions of acute and chronic exposure of $\mathrm{PN}$ on platelet function in platelet-rich plasma obtained from pigs [262]. The addition of PN (0.031$0.062 \mathrm{mM}-2 \mathrm{mM})$, but not decomposed PN to ovine platelets, produced immediate, concentration dependent inhibitory effect on thrombin- and to collagen-induced platelet adhesion, a first step in platelet activation [262]. Following platelet incubation with PN (0.25 mM-2 mM), lipid peroxidation increased in a dose dependent manner, whereas significant changes in platelet proteins were not seen [262]. These data suggest that peroxidation of platelet lipids induced by PN changes membrane structure and affects specific receptors inhibiting platelet adhesion or aggregation [262]. These authors suggest that lipid peroxidation of platelet membranes by PN modifies signal transduction and alters responses to thrombin and collagen, however the PN concentrations used in these experiments were high and may not represent physiologic conditions [262].

The actions of PN on platelet function are concentrationdependent, PN stimulates platelet aggregation at high concentrations [22], whereas at lower concentrations, or in presence of plasma, inhibits platelet aggregation [22, 241, 254]. This inhibition is cGMP-dependent because PN nitrosates thiols to form nitrosothiols that release NO and inhibit platelet activation [21, 22, 254]. However, PN also nitrates phenols such as tyrosine and phenylalanine that affects cellular function [134, 263, 264]. Protein nitration may interfere with protein phosphorylation signaling pathways with recent studies showing that nitrated proteins form in platelets undergoing collagen-induced aggregation [265-267]. Low, Sabetkar et al. examined the effects of PN on platelet function and to further understand the role of the NO-cGMP pathway and protein nitration in washed platelets and in platelet-rich plasma from human volunteers [268]. PN (3 $\mu \mathrm{M}-10 \mu \mathrm{M})$, but not decomposed $\mathrm{PN}$, inhibited thrombin-induced platelet aggregation, and the presence of ODQ, an inhibitor of soluble guanylate cyclase [197, 198, 254], did not influence the inhibition of thrombin-induced aggregation by PN [268]. The ability of PN to induce cGMP formation was compared to authentic NO solutions and these authors observed that $\mathrm{PN}$, when compared to NO, did not significantly increase the synthesis of cGMP above basal levels. These data suggest that the platelet inhibiting action of PN is independent of a cGMP mechanism. In a separate series of experiments, incubation of washed platelets with PN for up to one hour before stimulation with thrombin or collagen resulted in a temporary ( $<30 \mathrm{~min})$ inhibition of aggregation, and suggest that the actions of PN were transient and non-toxic as PN does not permanently impair the ability of platelets to respond to these agents [268]. The addition of PN to unstimulated platelets leads to a significant increase in nitrated cytosolic, but not in membrane, platelet proteins [268]. However, nitrotyrosine levels decreased to near normal after 60 minutes, suggesting that protein nitration by $\mathrm{PN}$ is reversible. Wide variation between human platelet preparations was observed in both the initial levels of nitration and in the speed of nitration loss. Finally, the influence of PN on platelet-signaling proteins was also investigated. The addition of thrombin to washed platelets increased a broad range of protein phosphorylation, however incubation of $\mathrm{PN}$ with washed platelets prior to thrombin stimulation led to decreases in protein phosphorylation, but that this inhibitory effect of PN was reversible in some proteins with platelet proteins recovering the ability to be phosphorylated within $15 \mathrm{~min}$. These data found that low PN concentrations can reversibly inhibit aggregation by preventing phosphorylation of key signaling proteins [268]. 
Table 2. Studies Examining the Anti-Platelet Aggregation Effects of PN

\begin{tabular}{|c|c|c|c|c|c|}
\hline Authors & & Model & $P N$ & Findings & Reference \\
\hline $\begin{array}{l}\text { Moro, Darley-Usmar } \\
\text { et al. } 1994\end{array}$ & $\begin{array}{l}\text { 1) } \\
\text { 2) }\end{array}$ & $\begin{array}{l}\text { Washed human plate- } \\
\text { let suspensions } \\
\text { Platelet-rich human } \\
\text { plasma }\end{array}$ & $20 \mu \mathrm{M}-200 \mu \mathrm{M}$ & $\begin{array}{l}\text { 1) Increases aggregation } \\
\text { 2) Decreases aggregation } \\
\text { Reversal of the aggregatory effect is observed } \\
\text { in washed platelets following the additions of } \\
\text { plasma, human serum albumin, or glutathione }\end{array}$ & [22] \\
\hline $\begin{array}{l}\text { Moro, Darley-Usmar et } \\
\text { al. } 1995\end{array}$ & $\begin{array}{l}\text { 1) } \\
\text { 2) }\end{array}$ & $\begin{array}{l}\text { Washed human plate- } \\
\text { let suspensions } \\
\text { Platelet-rich human } \\
\text { plasma }\end{array}$ & $20 \mathrm{mM}$ & $\begin{array}{l}\text { Platelet inhibition was dependent on the concen- } \\
\text { tration of D- or L-glucose }\end{array}$ & {$[61]$} \\
\hline Yin, Lai et al. & $\begin{array}{l}\text { 1) } \\
\text { 2) } \\
\text { 3) }\end{array}$ & $\begin{array}{l}\text { Platelet-rich plasma } \\
\text { Platelet-poor plasma } \\
\text { Human albumin }\end{array}$ & $50 \mu \mathrm{M}-200 \mu \mathrm{M}$ & $\begin{array}{l}\text { Inhibited platelet aggregation in a dose-dependent } \\
\text { manner to different aggregation agents, ADP, } \\
\text { collagen, thrombin, and U46619 } \\
\text { PN inhibition of aggregation requires protein } \\
\text { nitrosylation }\end{array}$ & [241] \\
\hline Brown, Moro et al. & $\begin{array}{l}\text { 1) } \\
\text { 2) }\end{array}$ & $\begin{array}{l}\text { Washed human plate- } \\
\text { lets } \\
\text { Human platelet-poor } \\
\text { plasma }\end{array}$ & $50 \mu \mathrm{M}-400 \mu \mathrm{M}$ & $\begin{array}{l}\text { 1) Induces aggregation by mobilization of } \mathrm{Ca}^{++} \\
\text {from the extracellular compartment } \\
\text { 2) Inhibited collagen-induced P-selectin ex- } \\
\text { pression } \\
\text { 3) Inhibition of aggregation due to conversion } \\
\text { to NO or NO donor } \\
\text { 4) Inhibition } v s \text { aggregation is concentration } \\
\text { dependent }\end{array}$ & [254] \\
\hline Boulos, Jiang et al. & & $\begin{array}{l}\text { ed human platelet } \\
\text { nsions }\end{array}$ & $\begin{array}{l}\text { 1) } 100-190 \mu \mathrm{M} \\
\text { 2) } 4-50 \mu \mathrm{M}\end{array}$ & $\begin{array}{l}\text { 1) Moderate aggregatory effect } \\
\text { 2) Inhibited aggregation in a dose-dependent } \\
\text { manner } \\
\text { Modulates eicosanoid synthesis } \\
\text { Timing of reactive species generation is important } \\
\text { in PN's effects on platelets }\end{array}$ & {$[256]$} \\
\hline Nowak and Wachowicz & & platelet-rich plasma & $\begin{array}{l}0.031-0.062 \mathrm{mM}-2 \\
\mathrm{mM}\end{array}$ & $\begin{array}{l}\text { Concentration dependent inhibitory effect on } \\
\text { thrombin- and to collagen-induced platelet adhe- } \\
\text { sion } \\
\text { Peroxidation of platelet lipids affects platelet } \\
\text { aggregation }\end{array}$ & {$[262]$} \\
\hline Low, Sabetkar et al. & & $\begin{array}{l}\text { Washed human plate- } \\
\text { lets } \\
\text { Platelet-rich plasma } \\
\text { from human volun- } \\
\text { teers }\end{array}$ & $3 \mu \mathrm{M}-10 \mu \mathrm{M}$ & $\begin{array}{l}\text { Wide variation between human platelet prepara- } \\
\text { tions was observed } \\
\text { Low concentrations can reversibly inhibit aggre- } \\
\text { gation by preventing phosphorylation of key sig- } \\
\text { naling proteins }\end{array}$ & {$[268]$} \\
\hline
\end{tabular}

ADP, adenosine diphosphate; PN, peroxynitrite.

\section{PROTECTIVE EFFECT OF PEROXYNITRITE IN ISCHEMIA REPERFUSION INJURY}

At nanomolar concentrations, $\mathrm{NO}$ modulates a number of physiologic processes related to vascular reactivity and platelet function $[228,269]$, leukocyte-endothelial cell interactions [270], vascular permeability [271, 272], and is cytoprotective in ischemia-reperfusion injury [273, 274]. However, at higher micromolar concentrations, $\mathrm{NO}$ as well as PN, participates in cellular injury as seen in the lung [243], following the development of ischemia-reperfusion injury, endotoxic and hypovolemic shock [7, 275]. Although vascular injury is linked to formation of toxic products from activated neutrophils [104], and that endothelial cells, macrophages and neutrophils can generate PN and induce membrane lipid peroxidation [57], the effects of PN on neutrophilendothelial cell interactions were largely unknown. Lefer, Scalia et al. investigated the effect of physiologic relevant concentrations of PN on neutrophil (PMN)-endothelial cell interactions [26]. In rat isolated aorta rings, PN $(5 \mu \mathrm{M})$, but not decomposed $\mathrm{PN}$, produced significant relaxation, whereas at concentrations of $50 \mathrm{nM}-500 \mathrm{nM}$, detectable responses were not seen [26]. These data show that PN in a macromolar range can exert significant vasorelaxant effects in isolated vessels. The administration of acetylcholine following the administration of $5 \mu \mathrm{M}$ of PN to the ring preparation produced a significant relaxation suggesting that PN does not impair endothelium dependent responses [26]. The effects of PN were observed on adherence to the endothelium of unstimulated PMNs following thrombin stimulation in isolated superior mesenteric artery. Thrombin stimulation increased PMNs adhesion rates by 7-fold, however, following the administration of PN $(100 \mathrm{nM})$, PMNs adhesion rates were significantly reduced [26]. The effects of PN on leukocyte rolling and adherence in mesenteric postcapillary venules were also examined and that thrombin or hydrogen 
peroxide markedly increased leukocyte rolling, but following administration of PN ( $800 \mathrm{nM})$, leukocyte rolling was significantly reduced [26]. However, these effects of PN were transient, as the addition of fresh thrombin at 2 hours to this preparation resulted in a return of leukocyte adherence and rolling, suggesting that $\mathrm{PN}$ does not irreversibly damage leukocytes or endothelial cells [26]. In separate series of experiments, the effects of PN $(800 \mathrm{nM})$ following induction of P-selectin with L-NAME were examined and pretreatment with PN significantly inhibited the L-NAME-mediated increases in leukocyte rolling and adherence, confirming that $\mathrm{NO}$ is an important modulator of leukocyte adhesion to the endothelium [26, 270]. Moreover, pretreatment with PN significantly reduced surface expression of P-selectin following stimulation with either L-NAME or thrombin, suggesting that nanomolar concentrations inhibit leukocyte-endothelial cell interactions by a P-selectin dependent mechanism [26]. The role of $\mathrm{PN}$ in attenuating leukocyte-endothelial interactions was tested in a myocardial ischemia reperfusion model. Perfused rat hearts were subjected to $20 \mathrm{~min}$ of ischemia followed by $45 \mathrm{~min}$ of reperfusion with and without PMNs, and the hearts reperfused in the presence of PMNs resulted in a significant sustained reduction in coronary flow and impaired ventricular function [26]. However, infusion of PN resulted in a significant degree of cardioprotection and cardiac perfusion and ventricular performance improved when compared to PMNs perfused hearts, and that postischemic coronary flow protection was less that observed in PMNsfree perfused heart, whereas ventricular performance was comparable to the PMN-free heart preparation [26]. Histological and myeloperoxidase activity analysis demonstrated that PN significantly attenuated PMNs infiltration into heart tissue and suggest that PN protects the ischemic/reperfused rat heart in large part by inhibiting PMNs accumulation [26]. These data show that PN in nanomolar concentrations can inhibit leukocyte-endothelial cell interactions, exert cytoprotective effects and that inhibition of P-selectin is a key mechanism in modulation of PNinhibited leukocyte-endothelial cell interactions [26].

Studies have shown that the extension of myocardial infarct into initially nonischemic border zone occurs during subsequent reperfusion of tissue [276]. Moreover, PN is released upon reperfusion of ischemic heart tissue [277]. A1though PN has been reported to exert cytotoxic effects at high doses [22, 57, 115], prior studies have shown that at physiologic concentrations, PN reduces PMNs adhesion to the endothelium and attenuates PMNs-mediated contractile dysfunction seen in the isolated perfused rat heart [26]. However, similar studies in vivo are lacking. Nossuli, Hayward et al. 1997 examined the role of PN in vivo in physiologically relevant concentrations in a feline model of myocardial reperfusion injury [25]. In feline hearts subjected to ischemia reperfusion, ischemia was induced by tightening a reversible silk ligature around the LAD for complete coronary occlusion of flow for 90 min followed by reperfusion of ischemic myocardium for $270 \mathrm{~min}$ [25]. In a subgroup of animals, $\mathrm{PN}(1 \mu \mathrm{M} / \mathrm{L})$ infusion was administered 10 minutes before reperfusion in cats subjected to myocardial ischemia and reperfusion. In those experiments, PN-treated animals demonstrated marked attenuation of cardiac necrosis when compared to control animals, but only in those animals administered the infusion via the intraventricular route, whereas with an intravenous method of PN infusion, the extent of necrosis was not significantly different between groups [25]. Early endothelial dysfunction is a critical event in PMN-mediated vascular injury $[26,56,278]$. The authors examined the response of endothelial-dependent vasodilators, acetylcholine and the calcium ionophore, A23187, to the endothelial-independent vasodilator, sodium nitrite, in coronary artery rings from ischemic/reperfused and in control animals [25]. Coronary artery rings obtained from animals subjected to myocardial ischemia and reperfusion exhibited marked attenuation of responses to the endothelialdependent vasodilators, when compared to the nonischemic controls animals, however, these rings retained full relaxation responses to sodium nitrite [25]. However in animals receiving intraventricular $\mathrm{PN}$-infusion prior to the myocardial insult, the isolated coronary artery rings demonstrated a significantly improved relaxation suggesting that PN exerts a vasculoprotective effect on coronary vascular endothelium following ischemic reperfusion insult [25]. To further assess the role of neutrophil adhesion to the vascular endothelium, the extent of neutrophil adherence to arterial segments obtained from ischemic/reperfused vascular beds were examined and compared to arterial segments obtained from control cats. Few neutrophils were adhered to the endothelium of LAD coronary artery segments obtained from control nonischemic cats, whereas in LAD segments isolated from ischemic/reperfused cats exhibited a marked increase in neutrophil adherence. In ischemic/reperfused animals that received PN infusion, the degree of neutrophil-endothelial adherence was greater than non-ischemic control animals but less than LAD segments isolated from ischemic/reperfused animals [25]. These data support the hypothesis that PN can significantly modulate neutrophil-endothelial interactions in an in vivo setting of ischemic/reperfusion injury [25]. These authors next examined the role of P-selectin expression in coronary venules from myocardial tissue at risk for ische$\mathrm{mia} /$ reperfusion and compared with areas not at risk. In animals subjected to ischemia/reperfusion, a significant increase in area of coronary venules staining positive for P-selectin was observed, whereas in those animals that received PN intraventricular infusion, then the ischemia/reperfusion insult, a significant attenuation of P-selectin expression was observed in the coronary microvasculature to levels that were not significantly different that those observed in control nonischemic animals [25]. These data further support the observations that P-selectin plays a role in neutrophil adherence and that PN can modulate P-selectin expression [25, 26]. Similar results were obtained following stimulation of non-ischemic/reperfused coronary artery segments exposed to thrombin where a significant increase in neutrophil adherence was observed, and that prior $\mathrm{PN}$-infusion significantly decreased neutrophil adherence to the endothelium [25]. These data provide evidence to support the hypothesis that physiologically relevant concentrations of PN, when directly infused into the left ventricle, can exert significant cardioprotective and vasculoprotective effects following myocardial ischemia/reperfusion, and that PN can partially attenuate neutrophil-endothelium interactions [25].

Earlier studies have shown cardioprotective and vasculoprotective effects of PN and a role in modulating neutrophilendothelial adherence in myocardial/reperfusion injury models $[25,26]$, however, the maximally achievable concentra- 
tions of PN to active these beneficial effects are not known. Moreover, the beneficial actions of PN may be due to the formation of S-nitrosothiols and PN may act as a NO carrier or PN can act as a direct NO donor. Nossuli, Hayward et al. 1998 examined the dose-response relationships following different concentrations of PN infusion in a model of myocardial ischemia/reperfusion and also investigated with the mechanisms responsible for these beneficial effects [279]. Animals were subjected to myocardial ischemia followed by reperfusion and were administered with different concentrations of PN $(0.2 \mu \mathrm{M}, 2 \mu \mathrm{M}$, or $20 \mu \mathrm{M})$ directly infused into the left ventricle beginning $10 \mathrm{~min}$ before and continued throughout the reperfusion period [279]. The infusions of PN were assessed in their ability to limit the progression of myocardial necrosis following reperfusion. Interestingly, only the middle dose $(2 \mu \mathrm{M})$ statistically protected the myocardium from developing a substantial amount of necrosis [279]. These data suggest that the maximally effective concentrations of $\mathrm{PN}$ were in the lower micromolar range (2 $\mu \mathrm{M})$ and the cardioprotective effects were not due to changes in hemodynamic, electrophysiological or hematologic variables [279]. In regard to endothelial injury, a significant decrease in response to acetylcholine, and the calcium ionophore, A23187, in animals receiving the cardiac insult, but in animals infused with the middle dose of PN $(2 \mu \mathrm{M})$ endothelial function was preserved, whereas in animals receiving either the low or high dose of PN $(0.2 \mu \mathrm{M}$ or $20 \mu \mathrm{M})$, endothelial dysfunction was comparable to that observed in animals subjected to myocardial ischemia/reper-fusion [279]. The extent of neutrophil adherence to coronary artery segments obtained at the conclusion of these experiments was examined, and again in those animals receiving the middle dose of PN $(2 \mu \mathrm{M})$, LAD segments exhibited a significantly lower neutrophil adherence that in those animals receiving the ischemia/reperfusion insult alone [279]. The role of surface expression of P-selectin was examined in this model, and the percentage of expression in the coronary microvasculature was significantly attenuated only with the infusion of PN at the $2 \mu \mathrm{M}$ dose [279]. These data suggest that only the $2 \mu \mathrm{M}$ dose was able to modulate surface expression of Pselectin, leukocyte adherence, and myocardial tissue protection and the significant cardioprotective mechanism may be due to reduced expression of adhesion molecules by PN on the vascular endothelium [279]. Coronary artery rings were denuded of endothelium, and challenged with PN $(10 \mu \mathrm{M}$ $40 \mu \mathrm{M})$ and in the presence or absence of hemoglobin $(100 \mu \mathrm{M})$, a known NO scavenger [1,34,64,65], PN relaxed these rings in the presence or absence of $\mathrm{Hgb}$. These findings suggest that PN does not directly donate NO under these conditions [279]. Finally, the role of PN leading to Snitrosothiol formation was examined, and using a wide concentration range $(1 \mu \mathrm{M}-1000 \mu \mathrm{M}), \mathrm{PN}$ was incubated with reduced GSH in the presence of a copper chelator, with the reaction products analyzed by HPLC, and observed the production of S-nitrosothiols. PN nitrosated GSH to form GSNO [279].

Reperfusion of ischemic myocardium is associated with the development of dysrhythmias [280-283], however ischemic preconditioning protects the heart from subsequent ischemic damage [283, 284], reduces the incidence of dysrhythmias $[285,286]$, and has been shown to preserve contractile function [287]. NO and superoxide production were increased following reperfusion of ischemic tissue [288]. $\mathrm{PN}$, the downstream molecule of these radicals, can also play a role in the pathophysiology of myocardial perfusion injury [289], although PN, at physiologic concentrations, has been shown to have cardioprotective effects [25, 26, 279]. Altug, Demiryürek et al. investigated the effect of exogenous PN on ischemic/reperfusion dysrhythmias in an isolated rat heart model [290]. The effects of three different infusions of PN $(0.4 \mu \mathrm{M} / \mathrm{ml} / \mathrm{min}, 4 \mu \mathrm{M} / \mathrm{ml} / \mathrm{min}$, and $40 \mu \mathrm{M} / \mathrm{ml} / \mathrm{min})$ were studied in a modified Langendorff preparation [291], and PN at the higher infusions of $(4 \mu \mathrm{M} / \mathrm{ml} / \mathrm{min}$ and $40 \mu \mathrm{M} / \mathrm{ml} / \mathrm{min})$ produced a significant increase in severe dysrhythmias whereas the lowest dose $(0.4 \mu \mathrm{M} / \mathrm{ml} / \mathrm{min})$ produced a small number of ventricular ectopic beats. Moreover, PN at this dose, produced a significant reduction in the incidence of ventricular fibrillation when compared to control animals [290]. The administration of PN did not produce any significant change in coronary artery perfusion pressure or pressure-rate index measured throughout the course of the experiment [290]. These data suggest that the lowest dose of PN reduced the development of ischemia/reperfusion dysrhythmias in physiologic salt-perfused hearts [290], whereas the higher doses increased the incidence of dysrhythmias and partially support the findings of Schultz et al. [292], and of Naseem, Kontos et al. [293] that partial inhibition of the elevated endogenous NO production found in ischemic states can improve myocardial function and reduce the incidence of ischemia/reperfusion dysrhythmias [293]. The administration of urate did not change the beneficial effects of $\mathrm{PN}$ on reperfusion-induced dysrhythmias [290] and suggest that although uric acid is a scavenger of PN [294], urate administered in these experiments was ineffective in modifying the incidence of ischemia/reperfusion and are in agreement with other studies [295]. The prior administration of L-NAME reduced the incidence of ventricular fibrillation, but did not affect the incidence of irreversible ventricular fibrillation, whereas the administration of superoxide dismutase with catalase significantly increased the incidence of irreversible ventricular fibrillation [290]. These results suggest that PN, at low concentrations, may exert favorable effects in decreasing the incidence of ischemia/reperfusion-induced dysrhythmias [290]. Moreover, the use of a cell-permeant antioxidant that reacts rapidly with PN, abolished the beneficial effect of PN [296].

Ischemic/reperfusion injury in the lung is common following surgical procedures such as in lung transplantation, pulmonary embolectomy, or more commonly, following cardiopulmonary bypass [297, 298]. Prior studies have shown that ischemic preconditioning provides significant protection to the lungs [299-301] and that ischemic preconditioning of the lung can be protective against subsequent ischemia/reperfusion injury [302, 303], but underlying mechanisms are not well understood. Turan and Demiryürek investigated the effects of exogenous administration of $\mathrm{PN}$ in isolated rat lungs and to examine the contribution of endogenous PN formation on preconditioning [304]. Isolated lungs were perfused by Krebs-Henseleit solution and inflated with room air. Lungs were preconditioned with either ischemia for 5 min or an infusion of PN $(10 \mu \mathrm{M})$, followed with $5 \mathrm{~min}$ reperfusion, and with $2 \mathrm{~h}$ of ischemia and $10 \mathrm{~min}$ reperfusion. The application of ischemic preconditioning maintained vascular responses following ischemia/reperfusion, and an infusion of PN could mimic the beneficial effects of precondi- 
Table 3. Protective Effect of Peroxynitrite in Ischemia Reperfusion Injury

\begin{tabular}{|c|c|c|c|c|}
\hline Authors & Model & $P N$ & Findings & Reference \\
\hline Lefer, Scalia et al. & $\begin{array}{l}\text { A) PMNs rolling and ad- } \\
\text { herence to the endothe- } \\
\text { lium } \\
\text { B) myocardial ischemia } \\
\text { reperfusion rat model }\end{array}$ & $\begin{array}{l}\text { A1) } 100-1000 \mathrm{nM} \\
\text { A2) } 800 \mathrm{nM} \\
\text { B1) } 800 \mathrm{nM} \text { infusion }\end{array}$ & $\begin{array}{l}\text { A1) PMNs adhesion rates were significantly } \\
\text { reduced } \\
\text { A2) Leukocyte rolling significantly reduced } \\
\text { B1) Inhibiting PMNs accumulation, with signifi- } \\
\text { cant cardio-protection, improved cardiac per- } \\
\text { fusion and ventricular performance } \\
\text { P-selectin inhibition }\end{array}$ & [26] \\
\hline $\begin{array}{l}\text { Nossuli, Hayward } \\
\text { et al. } 1997\end{array}$ & $\begin{array}{l}\text { 1) } \begin{array}{l}\text { Feline myocardial } \\
\text { reperfusion injury } \\
\text { model }\end{array} \\
\text { 2) } \\
\begin{array}{l}\text { Harvested isolated } \\
\text { coronary artery rings }\end{array}\end{array}$ & $1 \mu \mathrm{M} / \mathrm{L}$ infusion & $\begin{array}{l}\text { 1) Marked attenuation of cardiac necrosis } \\
\text { 2) Significantly improved ring relaxation } \\
\text { Attenuation of P-selectin expression }\end{array}$ & [25] \\
\hline $\begin{array}{l}\text { Nossuli, Hayward } \\
\text { et al. } 1998\end{array}$ & $\begin{array}{ll}\text { A) } & \begin{array}{l}\text { Feline myocardial } \\
\text { reperfusion injury } \\
\text { model }\end{array} \\
\text { B) } & \begin{array}{l}\text { Harvested isolated } \\
\text { coronary artery rings }\end{array}\end{array}$ & $\begin{array}{l}0.2 \mu \mathrm{M}, 2 \mu \mathrm{M} \text {, or } 20 \mu \mathrm{M} \\
\text { infusions }\end{array}$ & $\begin{array}{l}\text { Middle dose }(2 \mu \mathrm{M}) \text { : } \\
\text { A) Decreased myocardial necrosis and pre- } \\
\text { B1) Lerved endothelial function } \\
\text { B2) Lowered neutrophil adherence } \\
\text { PN does not directly donate NO } \\
\text { PN nitrosates glutathione }\end{array}$ & [279] \\
\hline $\begin{array}{l}\text { Altug, Demiryürek } \\
\text { et al. }\end{array}$ & $\begin{array}{l}\text { Modified Langendorff prepa- } \\
\text { ration rat model }\end{array}$ & $\begin{array}{l}0.4 \mu \mathrm{M} / \mathrm{ml} / \mathrm{min}, 4 \\
\mu \mathrm{M} / \mathrm{ml} / \mathrm{min} \text {, and } 40 \\
\mu \mathrm{M} / \mathrm{ml} / \mathrm{min}\end{array}$ & $\begin{array}{l}\text { Lowest dose }(0.4 \mu \mathrm{M} / \mathrm{ml} / \mathrm{min}) \text { significantly re- } \\
\text { ducted ventricular fibrillation incidence } \\
\text { Use of a cell-permeant antioxidant abolished bene- } \\
\text { ficial effects }\end{array}$ & {$[290]$} \\
\hline $\begin{array}{l}\text { Turan and } \\
\text { Demiryürek }\end{array}$ & $\begin{array}{l}\text { Krebs-Henseleit solution per- } \\
\text { fused rat lung model }\end{array}$ & $10 \mu \mathrm{M}$ infusion & $\begin{array}{l}\text { PARS inhibition reversed beneficial effects } \\
\text { Lung malondialdehyde levels were significantly } \\
\text { decreased }\end{array}$ & [304] \\
\hline
\end{tabular}

PMN; polymorphonuclear cells; PARS, poly(adenosine 5'-diphos-phoribose) synthase; PN, peroxynitrite.

tioning. However, the beneficial effects of PN infusion on vascular responses following ischemia/reperfusion injury could not be reduced in the presence of uric acid, a PN scavenging agent $[167,305,306]$. Moreover, the use of the PARS inhibitors, 3-aminobenzamid or nicotinamide, reversed the beneficial effects of ischemia and PN preconditioning [304]. The improved wet/dry weight ratios demonstrated that the ischemia preconditioning and PN infusion caused a marked reduction in lung edema [304]. Lung malondialdehyde levels were significantly decreased in ischemic and PN preconditioned groups [304]. The authors suggested that PN has a significant role in the protective effects of preconditioning [304].

\section{CONCLUSION}

Reactive oxygen species such as superoxide can react with NO in pathologic conditions leading to the formation of the potent oxidant, PN [307]. PN, when formed in inflammatory conditions, causes cytotoxic effects including lipid peroxidation and cell death [44, 57, 104, 307]. However, in the literature examined in this paper, $\mathrm{PN}$ has been shown to have beneficial effects in the cardiovascular system, but in other reviews, the biologic effects of PN are not beneficial [3, 9$19]$, hence the effects of PN can be paradoxical. These differences could well be due to the environment in which studies were conducted [308]. Studies in nonsanguineous environments have largely shown the cytotoxic properties of PN, whereas in vivo models or in blood-perfused ex vivo models, the beneficial effects of PN are observed, particularly when examined in appropriate physiological concentrations. Nonsanguineous studies may result in the conversion of PN into deleterious mediators with hydroxyl radical-like activities, whereas in physiologic studies, the beneficial actions of PN may be due to reaction of PN with plasma, red cell glutathione, or plasma cysteine and albumin, with the production of NO or an NO-donor like compound [308].

\section{ACKNOWLEDGEMENTS}

This research supported by NIH Grant HL62000, HL77421, ES10018, and RR16456.

\section{REFERENCES}

[1] Furchgott, R.F.; Vanhoutte, P.M. FASEB J., 1989, 3, 2007.

[2] Moncada, S.; Palmer, R.M.; Higgs, E.A. Pharmacol. Rev., 1991, 43, 109.

[3] Pacher, P.; Beckman, J.S.; Liaudet, L. Physiol. Rev., 2007, 87, 315.

[4] Koppenol, W.H. Redox Rep., 2001, 6, 339

[5] Beckman, J.S.; Beckman, T.W.; Chen, J.; Marshall, P.A.; Freeman, B.A. Proc. Natl. Acad. Sci. USA, 1990, 87, 1620.

[6] Uppu, R.M.; Nossaman, B.D.; Greco, A.J.; Fokin, A.; Murthy, S.N.; Fonseca, V.A.; Kadowitz, P.J. Clin. Exp. Pharmacol. Physiol., 2007, 34, 933.

[7] Szabó, C. Shock, 1996, 6, 79.

[8] Liu, P.; Hock, C.E.; Nagele, R.; Wong, P.Y. Am. J. Physiol., 1997, $272, \mathrm{H} 2327$.

[9] Zweier, J.L.; Talukder, M.A.H. Cardiovasc. Res., 2006, 70, 181.

[10] Ricciardolo, F.L.M.; Di, S.A.; Sabatini, F.; Folkerts, G. Eur. J. Pharmacol., 2006, 533, 240.

[11] Pannu, R.; Singh, I. Neurochem. Int., 2006, 49, 170.

[12] Oates, J.C.; Gilkeson, G.S. Clin. Immunol., 2006, 121, 243.

[13] Moncada, S.; Higgs, E.A. Handb. Exp. Pharmacol., 2006, 176(Pt 1), 213 . 
[14] Mladenka, P.; Simünek, T.; Hübl, M.; Hrdina, R. Free Radic. Res., 2006, 40, 263.

[15] Kamat, J.P. Indian J. Exp. Biol., 2006, 44, 436.

[16] Förstermann, U. Biol. Chem., 2006, 387, 1521.

[17] Ceriello, A. Endocr. Pract., 2006, 12(Suppl 1), 60.

[18] Touyz, R.M. Antioxid. Redox. Signal., 2005, 7, 1302.

[19] Rubbo, H.; O'Donnell, V. Toxicology, 2005, 208, 305.

[20] Murad, F.; Rapoport, R.M.; Fiscus, R. J. Cardiovasc. Pharmacol., 1985, 7, S111.

[21] Wu, M.; Pritchard, K.A.; Kaminski, P.M.; Fayngersh, R.P.; Hintze, T.H.; Wolin, M.S. Am. J. Physiol., 1994, 266, H2108.

[22] Moro, M.A.; Darley-Usmar, V.M.; Goodwin, D.A.; Read, N.G.; Zamora-Pino, R.; Feelisch, M.; Radomski, M.W.; Moncada, S. Proc. Natl. Acad. Sci. USA, 1994, 91, 6702.

[23] Liu, S.; Beckman, J.S.; Ku, D.D. J. Pharmacol. Exp. Ther., 1994, $268,1114$.

[24] Liu, P.; Xu, B.; Quilley, J.; Wong, P.Y. Am. J. Physiol. Cell Physiol., 2000, 279, C1970.

[25] Nossuli, T.O.; Hayward, R.; Scalia, R.; Lefer, A.M. Circulation, 1997, 96, 2317.

[26] Lefer, D.J.; Scalia, R.; Campbell, B.; Nossuli, T.; Hayward, R.; Salamon, M.; Grayson, J.; Lefer, A.M. J. Clin. Invest., 1997, 99, 684.

[27] Zweier, J.L.; Flaherty, J.T.; Weisfeldt, M.L. Proc. Natl. Acad. Sci. USA, 1987, 84, 1404.

[28] Pearson, P.J.; Lin, P.J.; Schaff, H.V. Ann. Thorac. Surg., 1991, 51, 788.

[29] Beckman, J.S. J. Dev. Physiol., 1991, 15, 53.

[30] Jaeschke, H.; Schini, V.B.; Farhood, A. Life Sci., 1992, 50, 1797.

[31] Ely, D.; Dunphy, G.; Dollwet, H.; Richter, H.; Sellke, F.; Azodi, M. Free Radic. Biol. Med., 1992, 12, 479

[32] Matheis, G.; Sherman, M.P.; Buckberg, G.D.; Haybron, D.M.; Young, H.H.; Ignarro, L.J. Am. J. Physiol., 1992, 262, H616.

[33] Gruetter, C.A.; Barry, B.K.; McNamara, D.B.; Gruetter, D.Y.; Kadowitz, P.J.; Ignarro, L. J. Cyclic Nucleotide Res., 1979, 5, 211.

[34] Gruetter, C.A.; Gruetter, D.Y.; Lyon, J.E.; Kadowitz, P.J.; Ignarro, L.J. J. Pharmacol. Exp. Ther., 1981, 219, 181.

[35] Ignarro, L.J.; Byrns, R.E.; Buga, G.M.; Wood, K.S. Circ Res., 1987, 61,866

[36] Tracey, W.R.; Linden, J.; Peach, M.J.; Johns, R.A. J. Pharmacol. Exp. Ther., 1990, 252, 922 .

[37] Gryglewski, R.J.; Palmer, R.M.; Moncada, S. Nature, 1986, 320, 454

[38] Kelm, M.; Schrader, J. Circ. Res., 1990, 66, 1561

[39] Deliconstantinos, G.; Villiotou, V.; Stavrides, J.C. Anticancer Res., 1994, 14, 2717.

[40] Tarpey, M.M.; Beckman, J.S.; Ischiropoulos, H.; Gore, J.Z.; Brock, T.A. FEBS Lett., 1995, 364, 314.

[41] Zhu, L.; Gunn, C.; Beckman, J.S. Arch. Biochem. Biophys., 1992, $298,452$.

[42] Rubanyi, G.M.; Vanhoutte, P.M. Am. J. Physiol., 1986, 250 , H822.

[43] Rubanyi, G.M.; Vanhoutte, P.M. Am. J. Physiol., 1986, 250, H815.

[44] Radi, R.; Beckman, J.S.; Bush, K.M.; Freeman, B.A. J. Biol. Chem., 1991, 266, 4244.

[45] Wolin, M.S.; Cherry, P.D.; Rodenburg, J.M.; Messina, E.J.; Kaley, G. J. Pharmacol. Exp. Ther., 1990, 254, 872.

[46] Cherry, P.D.; Omar, H.A.; Farrell, K.A.; Stuart, J.S.; Wolin, M.S. Am. J. Physiol. Heart Circ. Physiol., 1990, 259, H1056.

[47] Klein, S.M.; Cohen, G.; Cederbaum, A.I. Biochemistry, 1981, 20 , 6006.

[48] Radi, R.; Cosgrove, T.P.; Beckman, J.S.; Freeman, B.A. Biochem. J., 1993, 290(Pt 1), 51.

[49] Kikuchi, K.; Nagano, T.; Hayakawa, H.; Hirata, Y.; Hirobe, M. Anal. Chem., 1993, 65, 1794

[50] Ignarro, L.J. Circ Res., 1989, 65, 1.

[51] Meister, A. J. Biol. Chem., 1994, 269, 9397.

[52] Stamler, J.S.; Singel, D.J.; Loscalzo, J. Science Wash DC., 1992, 258,1898

[53] Wolin, M.S.; Wood, K.S.; Ignarro, L.J. J. Biol. Chem., 1982, 257, 133212

[54] Ignarro, L.J.; Lippton, H.; Edwards, J.C.; Baricos, W.H.; Hyman, A.L.; Kadowitz, P.J.; Gruetter, C.A. J. Pharmacol. Exp. Ther., 1981, 218, 739 .

[55] Plummer, J.L.; Smith, B.R.; Sies, H.; Bend, J.R. Methods Enzymol., $1981,77,50$.

[56] Moncada, S.; Higgs, A. N. Engl. J. Med., 1993, 329, 2002.
Radi, R.; Beckman, J.S.; Bush, K.M.; Freeman, B.A. Arch. Biochem. Biophys., 1991, 288, 481 .

Hogg, N.; Darley-Usmar, V.M.; Wilson, M.T.; Moncada, S. Biochem. J., 1992, 281(Pt 2), 419.

Villa, L.M.; Salas, E.; Darley-Usmar, V.M.; Radomski, M.W.; Moncada, S. Proc. Natl. Acad. Sci. USA, 1994, 91, 12383.

Gryglewski, R.J.; Moncada, S.; Palmer, R.M. Br. J. Pharmacol., 1986, 87,685 .

Moro, M.A.; Darley-Usmar, V.M.; Lizasoain, I.; Su, Y.; Knowles, R.G.; Radomski, M.W.; Moncada, S. Br. J. Pharmacol., 1995, 116, 1999.

Palmer, R.M.J.; Ferrige, A.G.; Moncada, S. Nature, 1987, 327, 524.

van der Vliet, A.; Smith, D.; O'Neill, C.A.; Kaur, H.; DarleyUsmar, V.; Cross, C.E.; Halliwell, B. Biochem. J., 1994, 303(Pt 1), 295.

Feelisch, M.; Noack, E.A. Eur. J. Pharmacol., 1987, 139, 19. Noack, E.; Feelisch, M. Basic Res. Cardiol., 1991, 86(Suppl 2), 37. Chong, S.; Fung, H.L. Biochem. Pharmacol., 1991, 42, 1433.

Myatt, L.; Brewer, A.; Brockman, D.E. Am. J. Obstet. Gynecol., $1991,164,687$.

Kadowitz, P.J.; Nandiwada, P.A.; Spannhake, E.W.; Rosenson, R.S.; McNamara, D.B.; Hyman, A.L. Chest, 1983, 83, 72S.

Holcberg, G.; Kossenjans, W.; Miodovnik, M.; Myatt, L. Am. J. Obstet. Gynecol., 1995, 173, 528.

Nozik, E.S.; Huang, Y.C.; Piantadosi, C.A. Respir. Physiol., 1995, 100,63 .

Radomski, M.W.; Salas, E. Atherosclerosis, 1995, 118 Suppl, S69.

Kooy, N.W.; Royall, J.A.; Lewis, S.J. Biol. Nitric Oxide, Portland Press, London. 1996. Care Med., 1992, 20, 864

Vallance, P.; Moncada, S. New Horiz., 1993, 1, 77.

Kooy, N.W.; Lewis, S.J. Eur. J. Pharmacol., 1996, 307, R5.

Myers, P.R.; Minor, R.L.; Guerra, R.; Bates, J.N.; Harrison, D.G. Nature, 1990, 345, 161.

Henry, P.J.; Drummer, O.H.; Horowitz, J.D. Br. J. Pharmacol., 1989, 98, 757.

Burke, T.M.; Wolin, M.S. Am. J. Physiol. Heart Circ. Physiol., 1987, 252, H721.

Taguchi, H.; Heistad, D.D.; Kitazono, T.; Faraci, F.M. Circ. Res., 1995, 76, 1057.

Wei, E.P.; Kontos, H.A. Hypertension, 1990, 16, 162.

McCarron, J.G.; Halpern, W. Am. J. Physiol., 1990, 259, H902. H1262.

271, H1498.

Katusic, Z.S.; Marshall, J.J.; Kontos, H.A.; Vanhoutte, P.M. Am. J. Physiol., 1989, 257, H1235.

Fujii, K.; Heistad, D.D.; Faraci, F.M. Circ. Res., 1991, 69, 697.

Radi, R.; Rodriguez, M.; Castro, L.; Telleri, R. Arch. Biochem. Biophys., 1994, 308, 89

Salgo, M.G.; Stone, K.; Squadrito, G.L.; Battista, J.R.; Pryor, W.A Biochem. Biophys. Res. Commun., 1995, 210, 1025.

Free Radic. Biol. Med., 1996, 21, 407.

Szabó, C. Free Radic. Biol. Med., 1996, 21, 855

Kooy, N.W.; Royall, J.A. Arch. Biochem. Biophys., 1994, 310, 352. Kooy, N.W.; Royall, J.A.; Ye, Y.Z.; Kelly, D.R.; Beckman, J.S. Am. J. Respir. Crit. Care Med., 1995, 151, 1250.

Zhang, J.; Dawson, V.L.; Dawson, T.M.; Snyder, S.H. Science, 1994, 263, 687.

Zingarelli, B.; O'Connor, M.; Wong, H.; Salzman, A.L.; Szabó, C. J. Immunol., 1996, 156, 350.

Shall, S. Princess Takamatsu Symposia, 1983, 13, 3. 283, 593

Caplan, A.I.; Rosenberg, M.J. Proc. Natl. Acad. Sci. USA, 1975, 72,1852 .

Terada, M.; Fujiki, H.; Marks, P.A.; Sugimura, T. Proc. Natl. Acad. Sci. USA, 1979, 76, 6411.

Kidwell, W.R.; Burdette, K.E. Biochem. Biophys. Res. Commun., 1974, 61, 766.

作, G.L.; Gross, S.D. Exp. Cell Res., 1978, 117, 127. 
[100] Szabó, C.; Zingarelli, B.; Salzman, A.L. Circ Res., 1996, 78, 1051.

[101] Royall, J.A.; Kooy, N.W.; Beckman, J.S. New Horiz., 1995, 3, 113.

[102] Haddad, I.Y.; Pataki, G.; Hu, P.; Galliani, C.; Beckman, J.S.; Matalon, S. J. Clin. Invest., 1994, 94, 2407.

[103] Haddad, I.Y.; Crow, J.P.; Hu, P.; Ye, Y.; Beckman, J.; Matalon, S. Am. J. Physiol., 1994, 267, L242.

[104] Mulligan, M.S.; Hevel, J.M.; Marletta, M.A.; Ward, P.A. Proc. Natl. Acad. Sci. USA, 1991, 88, 6338.

[105] Chabot, F.; Mitchell, J.A.; Quinlan, G.J.; Evans, T.W. Br. J. Pharmacol., 1997, 121, 485 .

[106] Nossaman, B.D.; Feng, C.J.; Kadowitz, P.J. Am. J. Physiol. Heart Circ. Physiol., 1994, 266, H2452.

[107] Banasik, M.; Komura, H.; Shimoyama, M.; Ueda, K. J. Biol. Chem., 1992, 267, 1569.

[108] Clancy, R.M.; Levartovsky, D.; Lesczynska-Piziak, J.; Yegudin, J.; Abramson, S.B. Proc. Natl. Acad. Sci. USA, 1994, 91, 3680.

[109] Mayer, B.; Schrammel, A.; Klatt, P.; Koesling, D.; Schmidt, K. J. Biol. Chem., 1995, 270, 17355.

[110] Stamler, J.S.; Simon, D.I.; Osborne, J.A.; Mullins, M.E.; Jaraki, O.; Michel, T.; Singel, D.J.; Loscalzo, J. Proc. Natl. Acad. Sci. USA, 1992, 89,444

[111] Meister, A. Cancer Res., 1994, 54, 1969s

[112] Fahey, R. C.; Sundquist, A. R. Adv. Enzymol. 1991, 64, 1.

[113] Monks, T.J.; Anders, M.W.; Dekant, W.; Stevens, J.L.; Lau, S.S.; van Bladeren, P.J. Toxicol. Appl. Pharmacol., 1990, 106, 1.

[114] Sies, H.; Sharov, V.S.; Klotz, L.O.; Briviba, K. J. Biol. Chem, 1997, 272, 27812.

[115] Sies, H.; de, G.H. Toxicol. Lett., 1992, 64-65 Spec No, 547.

[116] Fujioka, H.; Horiike, K.; Takahashi, M.; Ishida, T.; Kinoshita, M.; Nozaki, M. Experientia, 1993, 49, 47.

[117] Cheung, P.Y.; Schulz, R. Am. J. Physiol., 1997, 273, H1231.

[118] Moro, M.A.; Russel, R.J.; Cellek, S.; Lizasoain, I.; Su, Y.; DarleyUsmar, V.M.; Radomski, M.W.; Moncada, S. Proc. Natl. Acad. Sci. USA, 1996, 93, 1480 .

[119] Barker, J.E.; Heales, S.J.; Cassidy, A.; Bolaños, J.P.; Land, J.M.; Clark, J.B. Brain Res., 1996, 716, 118.

[120] Quast, U.; Cook, N.S. J. Pharmacol. Exp. Ther., 1989, 250, 261.

[121] Whiteman, M.; Kaur, H.; Halliwell, B. Ann. Rheum. Dis., 1996, 55, 383.

[122] Arnal, J.F.; Tack, I.; Besombes, J.P.; Pipy, B.; Negre-Salvayre, A. Am. J. Physiol. Cell Physiol., 1996, 271, C1521.

[123] Gordge, M.P.; Meyer, D.J.; Hothersall, J.; Neild, G.H.; Payne, N.N.; Noronha-Dutra, A. Br. J. Pharmacol., 1995, 114, 1083.

[124] Pryor, W.A.; Squadrito, G.L. Am. J. Physiol., 1995, 268, L699.

[125] Dowell, F.J.; Martin, W. Eur. J. Pharmacol., 1997, 338, 43.

[126] Van Dyke, K.; Antonini, J.M.; Wu, L.; Ye, Z.; Reasor, M.J. Agents Actions, 1994, 41, 44.

[127] Yu, L.; Gengaro, P.E.; Niederberger, M.; Burke, T.J.; Schrier, R.W. Proc. Natl. Acad. Sci. USA, 1994, 91, 1691.

[128] Gunasekar, P. G.; Kanthasamy, A.G.; Borowitz, J.L.; Isom, G.E. J. Neurochem., 1995, 65, 2016.

[129] Feelisch, M. Eur. Heart J., 1993, 14 Suppl I, 123.

[130] Feelisch, M. J. Cardiovasc, Pharmacol., 1991, 17, S25.

[131] Davidson, C.A.; Kaminski, P.M.; Wu, M.; Wolin, M.S. Am. J. Physiol. Heart Circ. Physiol., 1996, 270, H1038.

[132] Haddad, I.Y.; Ischiropoulos, H.; Holm, B.A.; Beckman, J.S.; Baker, J.R.; Matalon, S. Am. J. Physiol., 1993, 265, L555.

[133] Beckman, J.S.; Ischiropoulos, H.; Zhu, L.; van, d.W.M.; Smith, C.; Chen, J.; Harrison, J.; Martin, J.C.; Tsai, M. Arch. Biochem. Biophys., 1992, 298, 438 .

[134] Beckmann, J.S.; Ye, Y.Z.; Anderson, P.G.; Chen, J.; Accavitti, M.A.; Tarpey, M.M.; White, C.R. Biol. Chem. Hoppe. Seyler., 1994, 375, 81

[135] White, C.R.; Brock, T.A.; Chang, L.Y.; Crapo, J.; Briscoe, P.; Ku, D.; Bradley, W.A.; Gianturco, S.H.; Gore, J.; Freeman, B. A. Proc. Natl. Acad. Sci. USA, 1994, 91, 1044.

[136] Davidson, C.A.; Kaminski, P.M.; Wolin, M.S. Am. J. Physiol., 1997, 273, L437.

[137] Cross, A.R. Biochem. Pharmacol., 1987, 36, 489.

[138] Trujillo, M.; Alvarez, M.N.; Peluffo, G.; Freeman, B.A.; Radi, R. J. Biol. Chem., 1998, 273, 7828 .

[139] Furchgott, R.F.; Zawadzki, J.V. Nature, 1980, 288, 373.

[140] Ledenev, A.N.; Konstantinov, A.A.; Popava, E.; Ruuge, E.K. Biochem. Int., 1986, 13, 391 .

[141] Kosaka, T.; Koide, F.; Kuwabara, M.; Tanaka, S. Nippon Juigaku Zasshi, 1990, 52, 1043.
[142] Xie, Y.W.; Wolin, M.S. Circulation, 1996, 94, 2580.

[143] Soszyński, M.; Bartosz, G. Biochim. Biophys. Acta, 1996, 1291 107.

[144] Dowell, F.J.; Martin, W. Eur. J. Pharmacol., 1998, 344, 183.

[145] Martin, W.; Furchgott, R.F.; Villani, G.M.; Jothianandan, D. J. Pharmacol. Exp. Ther., 1986, 237, 529.

[146] Moncada, S.; Rees, D.D.; Schulz, R.; Palmer, R.M.J. Proc. Natl. Acad. Sci. USA, 1991, 88, 2166.

[147] Ignarro, L.J.; Kadowitz, P.J. Annu. Rev. Pharmacol. Toxicol., 1985, 25,171 .

[148] Hester, R.K. J. Pharmacol. Exp. Ther., 1985, 233, 100.

[149] Godfraind, T.; Egleme, C.; Osachie, I. Clin. Sci. (Lond)., 1985, 68, $65 \mathrm{~s}$.

[150] Karaki, H.; Murakami, K.; Urakawa, N. Arch. Int. Pharmacodyn. Ther., 1986, 280, 230.

[151] Taylor, C.J.; Meisheri, K.D. J. Pharmacol. Exp. Ther., 1986, 237, 803 .

[152] Standen, N.B.; Quayle, J.M.; Davies, N.W.; Brayden, J.E.; Huang Y.; Nelson, M.T. Science, 1989, 245, 177.

[153] Nelson, M.T.; Huang, Y.; Brayden, J.E.; Hescheler, J.; Standen, N.B. Nature, 1990, 344, 770 .

[154] Benkusky, N.A.; Lewis, S.J.; Kooy, N.W. Am. J. Physiol., 1998 $275, \mathrm{H} 501$.

[155] Upchurch, G.R.; Welch, G.N.; Loscalzo, J. Vasc. Med., 1996, 1, 25

[156] Gaston, B.; Reilly, J.; Drazen, J.M.; Fackler, J.; Ramdev, P.; Arnelle, D.; Mullins, M.E.; Sugarbaker, D.J.; Chee, C.; Singel, D.J. Proc. Natl. Acad. Sci. USA, 1993, 90, 10957.

[157] Stamler, J.S.; Jaraki, O.; Osborne, J.; Simon, D.I.; Keaney, J.; Vita, J.; Singel, D.; Valeri, C.R.; Loscalzo, J. Proc. Natl. Acad. Sci. USA 1992, 89, 7674.

[158] Arnelle, D.R.; Stamler, J.S. Arch. Biochem. Biophys., 1995, 318 , 279.

[159] Singh, R.J.; Hogg, N.; Joseph, J.; Kalyanaraman, B. J. Biol. Chem., 1996, 271, 18596 .

[160] Wilson, J.E.; du Vigneaud, V. J. Biol. Chem., 1950, 184, 63.

[161] Davisson, R.L.; Travis, M.D.; Bates, J.N.; Lewis, S. J. Circ Res. 1996, 79, 256.

[162] Travis, M.D.; Davisson, R.L.; Bates, J.N.; Lewis, S.J. Am. J. Physiol., 1997, 273, H1493.

[163] Graves, J.E.; Lewis, S.J.; Kooy, N.W. Am. J. Physiol., 1998, 274, H1001.

[164] Assreuy, J.; Cunha, F.Q.; Epperlein, M.; Noronha-Dutra, A.; O'Donnell, C.A.; Liew, F.Y.; Moncada, S. Eur. J. Immunol., 1994, 24,672 .

[165] Beckman, J.S.; Crow, J.P. Biochem. Soc. Trans., 1993, 21, 330.

[166] Swain, J.A.; Darley-Usmar, V.; Gutteridge, J. M. FEBS Lett., 1994 $342,49$.

[167] Becker, B.F.; Reinholz, N.; Leipert, B.; Raschke, P.; Permanetter, B.; Gerlach, E. Chest, 1991, 100, 176S.

[168] Wayner, D.D.M.; Burton, G.W.; Ingold, K.U.; Locke, S. FEBS Lett., 1985, 187, 33 .

[169] Frei, B.; Stocker, R.; Ames, B.N. Proc. Natl. Acad. Sci. USA, 1988 85,9748 .

[170] Becker, B.F. Free Radic. Biol. Med., 1993, 14, 615

[171] Skinner, K.A.; White, C.R.; Patel, R.; Tan, S.; Barnes, S.; Kirk, M.; Darley-Usmar, V.; Parks, D.A. J. Biol. Chem., 1998, 273, 24491.

[172] Schmidt, K.; Klatt, P.; Mayer, B. Biochem. J., 1994, 301(Pt 3), 645.

[173] Kelm, M.; Dahmann, R.; Wink, D.; Feelisch, M. J. Biol. Chem., 1997, 272, 9922

[174] Rubbo, H.; Radi, R.; Trujillo, M.; Telleri, R.; Kalyanaraman, B.; Barnes, S.; Kirk, M.; Freeman, B.A. J. Biol. Chem., 1994, 269 26066

[175] McCord, J.M.; Day, E.D. FEBS Lett., 1978, 86, 139.

[176] Laskin; Laskin. Methods, 1996, 10, 61.

[177] Thom, S.R.; Ischiropoulos, H. Res. Rep. Health Eff. Inst., 1997, 1

[178] Yoshie, Y.; Ohshima, H. Arch. Biochem. Biophys., 1997, 342, 13.

[179] Wei, E.P.; Kontos, H.A.; Beckman, J.S. Stroke, 1998, 29, 817.

[180] Quayle, J.M.; Nelson, M.T.; Standen, N.B. Physiol. Rev., 1997, 77, 1165.

[181] Faraci, F.M.; Heistad, D.D. Physiol. Rev., 1998, 78, 53

[182] Sobey, C.G.; Heistad, D.D.; Faraci, F.M. Stroke, 1997, $28,2290$.

[183] Ischiropoulos, H.; Zhu, L.; Chen, J.; Tsai, M.; Martin, J.C.; Smith, C.D.; Beckman, J.S. Arch. Biochem. Biophys., 1992, $298,431$.

[184] Myatt, L.; Rosenfield, R.B.; Eis, A.L.; Brockman, D.E.; Greer, I.; Lyall, F. Hypertension, 1996, 28, 488. 
[185] Roberts, J.M.; Taylor, R.N.; Musci, T.J.; Rodgers, G.M.; Hubel, C.A.; McLaughlin, M.K. Am. J. Obstet. Gynecol., 1989, 161, 1200.

[186] Freeman, B.A.; Crapo, J.D. J. Biol. Chem., 1981, 256, 10986.

[187] Okatani, Y.; Watanabe, K.; Wakatsuki, A.; Tamura, S.; Sagara, Y. Acta Obstet. Gynecol. Scand., 1998, 77, 883.

[188] Darley-Usmar, V.M.; Hogg, N.; O'Leary, V.J.; Wilson, M.T.; Moncada, S. Free Radic. Res. Commun., 1992, 17, 9.

[189] Okatani, Y.; Wakatsuki, A.; Morioka, N.; Watanabe, K. J. Pineal Res., 1999, 27, 111

[190] Münzel, T.; Heitzer, T.; Harrison, D.G. Herz, 1997, 22, 158.

[191] Wolin, M.S. Microcirculation, 1996, 3, 1.

[192] Pagano, P.J.; Griswold, M.C.; Najibi, S.; Marklund, S.L.; Cohen, R.A. Am. J. Physiol., 1999, 277, H2109.

[193] Ademolu, F.; Bagut, B.; Abaciolu, N.; Cakici, I. Pharmacology, 2002, 66, 1

[194] Li, J.; Li, W.; Altura, B.T.; Altura, B.M. Toxicol. Appl. Pharmacol., 2004, 196, 176.

[195] Brzezinska, A.K.; Gebremedhin, D.; Chilian, W.M.; Kalyanaraman, B.; Elliott, S.J. Am. J. Physiol. Heart Circ. Physiol., 2000, 278, $\mathrm{H} 1883$.

[196] Elliott, S.J.; Lacey, D.J.; Chilian, W.M.; Brzezinska, A.K. Am. J. Physiol., 1998, 275, H1585.

[197] Garthwaite, J.; Southam, E.; Boulton, C.L.; Nielsen, E.B.; Schmidt, K.; Mayer, B. Mol. Pharmacol., 1995, 48, 184.

[198] Schrammel, A.; Behrends, S.; Schmidt, K.; Koesling, D.; Mayer, B. Mol Pharmacol., 1996, 50, 1 .

[199] Stull, J.T.; Gallagher, P.J.; Herring, B.P.; Kamm, K.E. Hypertension, 1991, 17, 723 .

[200] Salvemini, D. Cell Mol. Life Sci., 1997, 53, 576.

[201] Landino, L.M.; Crews, B.C.; Timmons, M.D.; Morrow, J.D.; Marnett, L.J. Proc. Natl. Acad. Sci. USA, 1996, 93, 15069.

[202] Nossaman, B.D.; Dabisch, P.A.; Liles, J.T.; Baber, S.R.; Champion, H.C.; Kaye, A.D.; Feng, C.J.; Anwar, M.; Bivalacqua, T.J.; Santiago, J.A.; De, W.B.J.; Kadowitz, P.J. J. Appl. Physiol., 2004, 96, 455 .

[203] Benkusky, N.A.; Lewis, S.J.; Kooy, N.W. Eur. J. Pharmacol., 1999, 364,151

[204] Graves, J.E.; Lewis, S.J.; Kooy, N.W. J. Cardiovasc. Pharmacol., $\mathbf{2 0 0 5}, 46,646$.

[205] Li, J.; Li, W.; Altura, B.T.; Altura, B.M. Toxicol. Appl. Pharmacol., 2005, 209, 269.

[206] Islam, M.S.; Berggren, P.-O.; Larsson, O. FEBS Lett., 1993, 319, 128.

[207] Han, J.E.; Kim, E.; Ho, W.-K.; Earm, Y.E. Biochem. Biophys. Res. Commun., 1996, 219, 900

[208] Graves, J.E.; Lewis, S.J.; Kooy, N.W. J. Cardiovasc. Pharmacol., $\mathbf{2 0 0 5}, 46,653$.

[209] Graves, J.E.; Kooy, N.W.; Lewis, S.J. Br. J. Pharmacol., 2006, 148,7

[210] Nossaman, B.D.; Bivalacqua, T.J.; Champion, H.C.; Baber, S.R.; Kadowitz, P.J. J. Cardiovasc. Pharmacol., 2007, 50, 358.

[211] Moro, M.A.; Russel, R.J.; Cellek, S.; Lizasoain, I.; Su, Y.; DarleyUsmar, V.M.; Radomski, M.W.; Moncada, S. Proc. Natl. Acad. Sci. USA, 1996, 93, 1480.

[212] Francis, S.H.; Turko, I.V.; Corbin, J.D. Prog. Nucleic Acid Res. Mol. Biol., 2001, 65, 1.

[213] Rybalkin, S.D.; Yan, C.; Bornfeldt, K.E.; Beavo, J.A. Circ. Res., 2003, 93, 280 .

[214] Rybalkin, S.D.; Rybalkina, I.G.; Feil, R.; Hofmann, F.; Beavo, J.A. J. Biol. Chem., 2002, 277, 3310 .

[215] Feil, R.; Lohmann, S.M.; de Jonge, H.; Walter, U.; Hofmann, F. Circ. Res., 2003, 93, 907 .

[216] Bender, A.T.; Beavo, J.A. Pharmacol. Rev., 2006, 58, 488.

[217] Omori, K.; Kotera, J. Circ. Res., 2007, 100, 309.

[218] Zhao, K.S.; Liu, J.; Yang, G.Y.; Jin, C.; Huang, Q.; Huang, X. Clin. Hemorheol. Microcirc., 2000, 23, 259.

[219] White, C.R.; Moellering, D.; Patel, R.P.; Kirk, M.; Barnes, S.; Darley-Usmar, V. M. Biochem. J., 1997, 328, 517.

[220] Ronson, R.S.; Nakamura, M.; Vinten-Johansen, J. Cardiovasc. Res., 1999, 44, 47.

[221] Foresti, R.; Clark, J.E.; Green, C.J.; Motterlini, R. J. Biol. Chem., 1997, 272, 18411 .

[222] McMahon, T.J.; Ignarro, L.J.; Kadowitz, P.J. J. Appl. Physiol., 1993, 74, 1704.

[223] DeWitt, B.J.; Cheng, D.Y.; McMahon, T.J.; Nossaman, B.D.; Kadowitz, P.J. Am. J. Physiol., 1994, 266, H2256.
[224] McVeigh, G.E.; Brennan, G.M.; Johnston, G.D.; McDermott, B.J.; McGrath, L.T.; Henry, W.R.; Andrews, J.W.; Hayes, J.R. Diabetologia, 1993, 36, 33.

[225] Dzau, V.J. J. Cardiovasc. Pharmacol., 1990, 15 Suppl 5, S59.

[226] Cohen, R.A. Prog. Cardiovasc. Dis., 1995, 38, 105.

[227] Ignarro, L.J. FASEB J., 1989, 3, 31 .

[228] Radomski, M.W.; Palmer, R.M.J.; Moncada, S. Br. J. Pharmacol. $\mathbf{1 9 8 7}, 92,639$.

[229] Salas, E.; Moro, M.A.; Askew, S.; Hodson, H.F.; Butler, A.R.; Radomski, M.W.; Moncada, S. Br. J. Pharmacol., 1994, 4.

[230] Mellion, B.T.; Ignarro, L.J.; Myers, C.B.; Ohlstein, E.H.; Ballot, B.A.; Hyman, A.L.; Kadowitz, P.J. Mol. Pharmacol., 1983, 23, 653.

[231] Wayner, D.D.; Burton, G.W.; Ingold, K.U.; Barclay, L.R.; Locke, S.J. Biochim. Biophys. Acta., 1987, 924, 408.

[232] Church, D.F.; Pryor, W.A. Environ. Health Perspect., 1985, 64 111.

[233] Mellion, B.T.; Ignarro, L.J.; Ohlstein, E.H.; Pontecorvo, E.G.; Hyman, A.L.; Kadowitz, P.J. Blood, 1981, 57, 946.

[234] Pratico, D.; Iuliano, L.; Pulcinelli, F.M.; Bonavita, M.S.; Gazzaniga, P.P.; Violi, F. J. Lab. Clin. Med., 1992, 119, 364.

[235] Maresca, M.; Colao, C.; Leoncini, G. Cell Biochem Funct., 1992 10,79 .

[236] Leoncini, G.; Maresca, M.; Colao, C.; Piana, A.; Armani, U. Blood Coagul. Fibrinolysis, 1992, 3, 271

[237] Oury, T.D.; Tatro, L.; Ghio, A.J.; Piantadosi, C.A. Free Radic. Res., 1995, 23, 537.

[238] Naseem, K.M.; Bruckdorfer, K.R. Biochem. J., 1995, 310(Pt 1), 149.

[239] Akaike, T.; Yoshida, M.; Miyamoto, Y.; Sato, K.; Kohno, M.; Sasamoto, K.; Miyazaki, K.; Ueda, S.; Maeda, H. Biochemistry, 1993, 32, 827.

[240] Ischiropoulos, H.; Zhu, L.; Beckman, J.S. Arch. Biochem. Biophys., 1992, 298, 446.

[241] Yin, K.; Lai, P.S.; Rodriguez, A.; Spur, B.W.; Wong, P.Y. Prostaglandins, 1995, 50, 169 .

[242] Sargeant, P.; Farndale, R.W.; Sage, S.O. J. Biol. Chem., 1993, 268 , 18151.

[243] Wizemann, T.M.; Gardner, C.R.; Laskin, J.D.; Quinones, S.; Durham, S.K.; Goller, N.L.; Ohnishi, S.T.; Laskin, D.L. J. Leukoc. Biol., 1994, 56, 759 .

[244] Ischiropoulos, H.; Al-Mehdi, A.B. FEBS Lett., 1995, 364, 279.

[245] Czapski, G.; Goldstein, S. Free Radic. Biol. Med., 1995, 19, 785.

[246] Deliconstantinos, G.; Villiotou, V.; Stavrides, J.C.; Salemes, N.; Gogas, J. Anticancer Res., 1995, 15, 1435.

[247] Leeuwenburgh, C.; Hardy, M.M.; Hazen, S.L.; Wagner, P.; Ohishi, S.; Steinbrecher, U.P.; Heinecke, J.W. J. Biol. Chem., 1997, $272,1433$.

[248] Beckman, J.S.; Koppenol, W.H. Am. J. Physiol., 1996, 271, C1424.

[249] Sherman, M.P.; Griscavage, J.M.; Ignarro, L.J. Med. Hypotheses, 1992, 39, 143.

[250] Mondoro, T.H.; Shafer, B.C.; Vostal, J.G. Free Radic. Biol. Med., 1997, 22, 1055.

[251] Cheung, P.Y.; Salas, E.; Schulz, R.; Radomski, M.W. Semin. Perinatol., 1997, 21, 409.

[252] Wink, D.A.; Cook, J.A.; Kim, S.Y.; Vodovotz, Y.; Pacelli, R.; Krishna, M.C.; Russo, A.; Mitchell, J.B.; Jourd'heuil, D.; Miles, A.M.; Grisham, M.B. J. Biol. Chem., 1997, 272, 11147.

[253] Mannel, D.N.; Grau, G.E. Mol. Pathol., 1997, 50, 175.

[254] Brown, A.S.; Moro, M.A.; Masse, J.M.; Cramer, E.M.; Radomski, M.; Darley-Usmar, V. Cardiovasc. Res., 1998, 40, 380.

[255] van der Vliet, A.; Eiserich, J.P.; O'Neill, C.A.; Halliwell, B.; Cross, C.E. Arch. Biochem. Biophys., 1995, 319, 341.

[256] Boulos, C.; Jiang, H.; Balazy, M. J. Pharmacol. Exp. Ther., 2000 293, 222

[257] Fiala, E.S.; Sodum, R.S.; Bhattacharya, M.; Li, H. Experientia, 1996, $52,922$.

[258] Darley-Usmar, V.; White, R. Exp. Physiol., 1997, 82, 305.

[259] Arteel, G.E.; Briviba, K.; Sies, H. FEBS Lett., 1999, 445, 226.

[260] Bartosz, G. Acta Biochim. Pol., 1996, 43, 645.

[261] Ducrocq, C.; Blanchard, B.; Pignatelli, B.; Ohshima, H. Cell Mol. Life Sci., 1999, 55, 1068 .

[262] Nowak, P.; Wachowicz, B. Platelets, 2001, 12, 376

[263] van der Vliet, A.; O'Neill, C.A.; Halliwell, B.; Cross, C.E.; Kaur, H. FEBS Lett., 1994, 339, 89. 
[264] Salman-Tabcheh, S.; Guérin, M.C.; Torreilles, J. Free Radic. Biol. Med., 1995, 19, 695.

[265] Naseem, K.M.; Low, S.Y.; Sabetkar, M.; Bradley, N.J.; Khan, J.; Jacobs, M.; Bruckdorfer, K.R. FEBS Lett., 2000, 473, 119.

[266] Kong, S.K.; Yim, M.B.; Stadtman, E.R.; Chock, P.B. Proc. Natl. Acad. Sci. USA, 1996, 93, 3377.

[267] Gow, A.J.; Duran, D.; Malcolm, S.; Ischiropoulos, H. FEBS Lett., 1996, 385,63 .

[268] Low, S.Y.; Sabetkar, M.; Bruckdorfer, K.R.; Naseem, K.M. FEBS Lett., 2002, 511, 59.

[269] Radomski, M.W.; Palmer, R.M.; Moncada, S. Lancet, 1987, 2, 1057.

[270] Kubes, P.; Suzuki, M.; Granger, D.N. Proc. Natl. Acad. Sci. USA, 1991, 88, 4651 .

[271] Kurose, I.; Kubes, P.; Wolf, R.; Anderson, D.C.; Paulson, J.; Miyasaka, M.; Granger, D.N. Circ. Res., 1993, 73, 164.

[272] Moore, T.M.; Khimenko, P.L.; Wilson, P.S.; Taylor, A.E. Am. J. Physiol., 1996, 271, H1970.

[273] Siegfried, M.R.; Carey, C.; Ma, X.L.; Lefer, A.M. Am. J. Physiol., 1992, 263, H771.

[274] Pabla, R.; Buda, A. J.; Flynn, D.M.; Blesse, S.A.; Shin, A.M.; Curtis, M.J.; Lefer, D.J. Circ. Res., 1996, 78, 65.

[275] Szabó, C. New Horiz., 1995, 3, 2

[276] Farb, A.; Kolodgie, F.D.; Jenkins, M.; Virmani, R. J. Am. Coll. Cardiol., 1993, 21, 1245

[277] Yasmin, W.; Strynadka, K.D.; Schulz, R. Cardiovasc. Res., 1997, 33,422

[278] Fullerton, D.A.; Eisenach, J.H.; McIntyre, R.C., Jr.; Friese, R.S.; Sheridan, B.C.; Roe, G.B.; Agrafojo, J.; Banerjee, A.; Harken, A.H. Am. J. Physiol., 1996, 271, L326.

[279] Nossuli, T.O.; Hayward, R.; Jensen, D.; Scalia, R.; Lefer, A.M. Am. J. Physiol., 1998, 275, H509.

[280] Jennings, R.B.; Murry, C.E.; Reimer, K. A. Cardiovasc. Drugs Therapy, 1991, 5, 933 .

[281] Richard, V.J.; Murry, C.E.; Jennings, R.B.; Reimer, K.A. Fundam. Clin. Pharmacol., 1990, 4, 85.

[282] Go, L.O.; Murry, C.E.; Richard, V.J.; Weischedel, G.R.; Jennings, R.B.; Reimer, K.A. Am. J. Physiol., 1988, 255, H1188.

[283] Murry, C.E.; Jennings, R.B.; Reimer, K.A. Circulation, 1986, 74, 1124.

[284] Liu, Y.; Downey, J.M. Am. J. Physiol., 1992, 263, H1107.
[285] Hagar, J.M.; Hale, S.L.; Kloner, R.A. Circ. Res., 1991, 68, 61

[286] Vegh, A.; Szekeres, L.; Parratt, J. Br. J. Pharmacol., 1992, 107, 648.

[287] Kimura, Y.; Iyengar, J.; Subramanian, R.; Cordis, G.A.; Das, D.K. Basic Res. Cardiol., 1992, 87, 128.

[288] Wang, P.; Zweier, J.L. J. Biol. Chem., 1996, 271, 29223.

[289] Beckman, J.S.; Chen, J.; Ischiropoulos, H.; Crow, J.P.; Lester, P. Methods in Enzymology. Academic Press. 1994.

[290] Altug, S.; Demiryürek, A.T.; Cakici, I.; Kanzik, I. Eur. J. Pharmacol., 1999, 384, 157.

[291] Piacentini, L.; Wainwright, C.L.; Parratt, J.R. Cardiovasc. Res., 1993, 27, 674 .

[292] Schulz, R.; Dodge, K.L.; Lopaschuk, G.D.; Clanachan, A.S. Am. J. Physiol., 1997, 272, H1212.

[293] Naseem, S.A.; Kontos, M.C.; Rao, P.S.; Jesse, R.L.; Hess, M.L.; Kukreja, R.C. J. Mol. Cell Cardiol., 1995, 27, 419.

[294] Hooper, D.C.; Spitsin, S.; Kean, R.B.; Champion, J.M.; Dickson, G.M.; Chaudhry, I.; Koprowski, H. Proc. Natl. Acad. Sci. USA, 1998, 95, 675

[295] Lacoursiere, L.; Kingma, J.G., Jr. Free Radic. Biol. Med., 1991, 11, 319.

[296] Altug, S.; Demiryürek, A.T.; Kane, K.A.; Kanzik, I. Br. J. Pharmacol., 2000, 130, 125 .

[297] Ar'Rajab, A.; Dawidson, I.; Fabia, R. New Horiz,. 1996, 4, 224.

[298] Hawaleshka, A.; Jacobsohn, E. Can. J. Anaesth., 1998, 45, 670.

[299] Du, Z.Y.; Hicks, M.; Winlaw, D.; Spratt, P.; Macdonald, P. J. Heart Lung Transplant., 1996, 15, 1258.

[300] Li, G.; Chen, S.; Lou, W.; Lu, E. Chest, 1998, 113, 1356.

[301] Gasparri, R.I.; Jannis, N.C.; Flameng, W.J.; Lerut, T.E.; Van Raemdonck, D.E. Eur. J. Cardiothoracic Surg., 1999, 16, 639.

[302] Soncul, H.; Oz, E.; Kalaycioglu, S. Chest, 1999, 115, 1672.

[303] Li, G.; Chen, S.; Lu, E.; Hu, T. Thorac. Cardiovasc. Surg., 1999 47,38 .

[304] Turan, N.N.; Demiryürek, A.T. Pharmacol. Res., 2006, 54, 380.

[305] Regoli, F.; Winston, G.W. Toxicol. Appl. Pharmacol., 1999, 156, 96.

[306] Scott, G.S.; Hooper, D.C. Med. Hypotheses, 2001, 56, 95.

[307] Stamler, J.S. Cell, 1994, 78, 931.

[308] Ronson, R.S.; Thourani, V.H.; Ma, X.L.; Katzmark, S.L.; Han, D.; Zhao, Z.Q.; Nakamura, M.; Guyton, R.A.; Vinten-Johansen, J. Circulation, 1999, 100, II384.

(C) Nossaman and Kadowitz; Licensee Bentham Open.

This is an open access article distributed under the terms of the Creative Commons Attribution License (http://creativecommons.org/licenses/by/2.5/), which permits unrestrictive use, distribution, and reproduction in any medium, provided the original work is properly cited. 